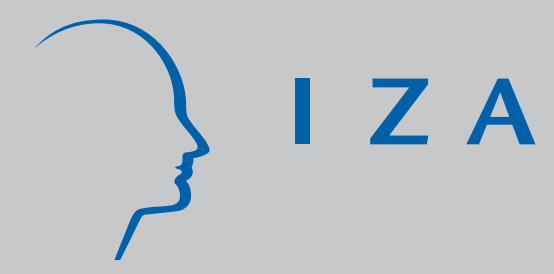

IZA DP No. 3397

War and Endogenous Democracy

Davide Ticchi

Andrea Vindigni

March 2008 


\title{
War and Endogenous Democracy
}

\author{
Davide Ticchi \\ University of Urbino \\ Andrea Vindigni \\ Princeton University \\ and IZA

\section{Discussion Paper No. 3397 \\ March 2008} \\ IZA \\ P.O. Box 7240 \\ 53072 Bonn \\ Germany \\ Phone: +49-228-3894-0 \\ Fax: +49-228-3894-180 \\ E-mail: iza@iza.org
}

Any opinions expressed here are those of the author(s) and not those of IZA. Research published in this series may include views on policy, but the institute itself takes no institutional policy positions.

The Institute for the Study of Labor (IZA) in Bonn is a local and virtual international research center and a place of communication between science, politics and business. IZA is an independent nonprofit organization supported by Deutsche Post World Net. The center is associated with the University of Bonn and offers a stimulating research environment through its international network, workshops and conferences, data service, project support, research visits and doctoral program. IZA engages in (i) original and internationally competitive research in all fields of labor economics, (ii) development of policy concepts, and (iii) dissemination of research results and concepts to the interested public.

IZA Discussion Papers often represent preliminary work and are circulated to encourage discussion. Citation of such a paper should account for its provisional character. A revised version may be available directly from the author. 


\section{ABSTRACT}

\section{War and Endogenous Democracy*}

Many episodes of extension of franchise in the $19^{\text {th }}$ and especially in the $20^{\text {th }}$ century occurred during or in the aftermath of major wars. Motivated by this fact, we offer a theory of political transitions which focuses on the impact of international conflicts on domestic political institutions. We argue that mass-armies, which appeared in Europe after the French Revolution, are an effective military organization only if the conscripted citizens are willing to put effort in fighting wars, which in turn depends on the economic incentives that are provided to them. The need to provide such incentives implies that an oligarchy adopting a mass-army may voluntarily decide to promise some amount of income redistribution to its citizens, conditionally on satisfactory performance as soldiers. When the elite cannot credibly commit to provide an incentive-compatible redistribution, they may cope with the moral hazard problem of the citizens-soldiers only by relinquishing political power to them through the extension of franchise. This is because democracy always implements a highly redistributive fiscal policy, which makes fighting hard incentive-compatible for the citizens-soldiers. We show that a transition to democracy is more likely to occur when the external threat faced by an incumbent oligarchy is in some sense intermediate. A very high external threat allows the elite to make credible commitments of future income redistribution in favor of the citizens, while a limited external threat makes optimal for the elite not making any (economic or political) concession to the masses. Some historical evidence consistent with our theory is also provided.

JEL Classification: P16, H11

Keywords: autocracy, democracy, wars, redistribution

Corresponding author:

Andrea Vindigni

Department of Politics

Princeton University

Princeton, NJ 08544-1012

USA

E-mail: vindigni@princeton.edu

\footnotetext{
* A previous version of this paper circulated under the title "On Wars and Political Development. The Role of International Conflicts in the Democratization of the West." Part of this paper was written while Davide Ticchi was at Universitat Pompeu Fabra whose hospitality is gratefully acknowledged. We thank Roland Bénabou, Avner Greif, Howard Rosenthal and seminar participants at UC Berkeley, the Institute for International Economic Studies (Stockholm), Princeton University, University of Urbino and Yale University for useful comments. We are especially grateful to Daron Acemoglu and James Robinson for encouragements, conversations and many useful comments and suggestions. The usual disclaimers apply.
} 
"The basis of democratization is everywhere purely military in character... Military discipline meant the triumph of democracy because the community wished and was compelled to secure the cooperation of the non-aristocratic masses and hence put arms, and along with arms political power, into their hands." Max Weber (1950 pp. 325-326).

\section{Introduction}

The process of politico-economic development of the Western world has been marked, during the $19^{\text {th }}$ and $20^{\text {th }}$ century, by two distinctive trends: the progressive extension of franchise and consolidation of democratic institutions, and the increasing fiscal redistribution of income promoted by the governments. According to the standard positive theory of taxation and redistribution (e.g. Romer 1975, Roberts 1977, Meltzer and Richard 1981), these trends are intimately related since the extension of franchise, by reducing the income of the median voter relative to the mean income, should be expected to generate the political support for a more redistributive fiscal policy. However, because higher taxation is detrimental to the interests of the rich, the question of why an oligarchic government, representing the interests of the economic elite, should ever extend franchise rights to the lower classes naturally suggests itself.

This paper attempts to provide an answer to the question of the rationale for the extension of franchise in the Western world, which emphasizes the importance of international warfare for the endogenous evolution of political institutions. ${ }^{1}$ Our theory is motivated by the observation that many episodes of extension of voting rights and of consolidation of democracy occurred in the West during, and more often in the aftermath, of the waging of major wars. For example universal suffrage, i.e. the provision of the right to vote with no qualification to the whole adult male and female population, was first introduced in Austria in 1918, in Belgium in 1948, in Denmark in 1915, in France in 1946, in Germany in 1919, in Italy in 1946, in the Netherlands in 1919, in Norway in 1915, and in Sweden in 1918. ${ }^{2}$ Canada, adopted universal suffrage with some voting qualifications in 1920, and Finland did so in 1919. In the U.K., a large portion of adult male population had been enfranchised by end of the $19^{\text {th }}$ century, but some voting qualifications had been kept in place; these restrictions were eventually removed only in 1918 .

The theory of democratic transitions proposed in this paper rests on two main factual

\footnotetext{
${ }^{1}$ From now on, we will use the expressions "extension of franchise" and "concession of democracy" interchangeably.

${ }^{2}$ In some of these countries, universal male suffrage was introduced sometime before universal suffrage was. For instance, universal male suffrage was introduced in Belgium in 1919, in Italy in 1919 (when a number of voting qualifications contemplated by previous electoral law of 1911 were removed), and in the Netherlands in 1917. See also Therborn (1977 p. 11, table 2).
} 
assumptions. The first assumption is the existence of fragmentation and rivalry within a system of states generating the threat of outbreak of military conflicts. The second assumption, equally important, is that of a widespread use of a military technology based on the deployment of mass-armies. We argue that, under these conditions, an oligarchic government may voluntarily decide to make economic or political concessions, i.e. to promise some income redistribution or to concede a franchise extension, in order to provide to the citizens the incentives to undertake a costly action - fighting hard in battle - which is beneficial to the elite themselves. By credibly promising some redistribution of income to the citizens, the elite can cope with the moral hazard problem potentially arising when the citizens are conscripted in mass-armies. However, because a war does not occur at any period of time, an incentive-compatible redistribution may not be always credibly promised to the citizens, due to the incentive that the elite have of reneging on past promises when a period of peace eventually comes. If a credible promise of income redistribution cannot be made by the elite to the citizens, the only way the elite may cope with the moral hazard problem of the citizens-soldiers is by relinquishing political power through the extension of franchise. The extension of franchise may allow the elite to commit to an incentive-compatible redistribution, since it involves a permanent reallocation of political power to the citizens. On the other hand, because democracy implements a highly redistributive fiscal policy, conceding it allows to cope with the moral hazard problem of the citizens-soldiers.

In practice, radical changes in political institutions, such as a substantial extension of franchise, are rarely observed in times of hostilities, arguably because of the fear that they may exacerbate domestic political instability, and thus have highly undesirable negative effects on the ability to wage war successfully. Nonetheless, even if some constraint prevents the concession of democracy in war times, we demonstrate that the promise of an extension of franchise at the end of a war may itself provide to the elite some additional leeway to commit to future redistribution. This is the case if the likelihood of occurrence of a war is potentially variable over time and, in particular, it is relatively high in the aftermath of a war, and lower after a protracted period of peace. If a new conflict is expected to occur with relatively high probability following the conclusion of a war, the elite may credibly promise during the period of war to concede democracy at the end of the conflict, because of the high expected cost of breaking the promise of democratization. More precisely, we show that democracy can be credibly promised in a period of war (when political institutions cannot be changed by assumption), and then conceded in the period of peace immediately following, in a trigger-type subgame perfect equilibrium (SPE). This equilibrium is supported by the (credible) threat of 
the citizens of putting no effort in fighting future wars, if the elite deviate from a promise of democratization. We also show that the same reputational mechanism supporting the promise of democracy, may not support a mere (intertemporal) promise of redistribution. This is because the elite may prefer to deviate from the promise in question, once a transition to a state of relative insulation from war (i.e. where the probability of outbreak of a new war in the future is relatively small) eventually happens. It must be emphasized at this point that focusing on a history-dependent SPE, rather than on a Markov perfect equilibrium, is essential in our model since, in a Markovian equilibrium, it would never be optimal for the elite to fulfill the promise to extend franchise after the end of a war. ${ }^{3}$

We also show that a transition to democracy is more likely to occur when the threat posed by war to the oligarchy in power, in terms of the income disruption caused by a military defeat, is intermediate. A very high external threat increases the ability of the elite to make credible commitments to the citizens, as it makes more costly for the elite to break a promise of income redistribution. This makes the elite more likely to implement redistributive policies, but not political reforms. A very limited external threat makes either economic and political concessions too expensive for the elite relative to the expected cost of losing a war, and therefore no concessions are made. Finally, an intermediate degree of external threat induces the elite to prefer avoiding a military defeat, but does not enable them to make credible promises of incentive-compatible redistribution. Hence, the extension of franchise is the strategy that the elite can pursue in order to exploit the military potential of mass-army.

Two important qualifications are worthwhile remarking. First, our theory makes only a conditional statement regarding the relationship between warfare and democratization. Specifically, our theory suggests that warfare may lead to democracy only when wars are waged through mass-armies, based on the conscription of large parts of the population and in particular of the lower classes, rather than on professional militaries formed by volunteer soldiers. ${ }^{4}$ Second, while the focus of our paper is on the impact of mass warfare on the birth of modern democracy and modern welfare state in the West, the core proposition of our theory, according

\footnotetext{
${ }^{3}$ The equilibrium concept adopted reflects a crucial difference between our model and other models of political transitions such as Acemoglu and Robinson (2000, 2001 and 2006), who focus on the Markov perfect equilibrium of a dynamic political game. Because in their setup democracy can be conceded at any point in time, nothing substantial is lost by neglecting other SPEs. Conversely, because in our model democracy can only be promised in periods of wars, reputational factors are crucial in supporting an equilibrium with democratization.

${ }^{4}$ For example, Downing (1992) argues that the international warfare mounting among European nations at the beginning of the Modern Era, had the effect of wiping out the parliamentary institutions existing in Continental Europe which, as he claims, contained the seeds of modern representative democracy. This view is not in contradiction with our theory, as the military technology adopted in the West all through the Modern Era was based on the deployment of professional militaries, rather than on mass-armies as we assume.
} 
to which political and social rights are the counterpart of military duties, has potentially a much wider scope. In fact, a causal relation between changes in the military organization determining an extension of military duties to broader portions of society, and a politico-institutional evolution toward more inclusive forms of government, can be observed in the history of the Western, and non-Western, world, well before the $19^{\text {th }}$ century. ${ }^{5}$

Our model sheds some new light on many important cases of democratic transitions occurred in Western countries during the last two centuries. In particular, we can explain the divergent evolution of political institutions in Prussia/Germany, which developed a welfare state but did not democratize, with respect to countries such as England and the U.S., which all experienced a progressive extension of voting rights, culminated in universal suffrage. We also argue that the concession of the right to vote to women in the first half of the $20^{\text {th }}$ century, can be interpreted as the counterpart of their participation to the waging of total wars, for instance by substituting the men at the front in factories and other productive activities. Finally, we can provide a rationale of why democracy failed to consolidate in geographic areas, such as Latin America and Africa, which have been largely insulated from the episodes of mass warfare experienced by Europe and by the U.S. during the $20^{\text {th }}$ century.

The existence of a link between mass warfare and the extension of political rights, similar to the one suggested by our theory, has been widely recognized by political scientists and historians, including among others Weber (1950), Titmuss (1958), Andreski (1968), Marwick (1974), Therborn (1977), Giddens (1987), Mann (1988), Hobsbawm (1990), Porter (1994), Keyssar (2000), Dolman (2004) and Halperin (2004). ${ }^{6}$ However, none of these authors clearly specifies a casual mechanism linking war and democratization, nor emphasizes the importance of democracy for the credible provision of incentives to citizens-soldiers, which is a distinctive feature of our theory. Also, none of the works cited above clarifies why the promise of democracy made to the masses in war times is often fulfilled by the elite once the war, and the related threat faced by the elite, has ended. Finally, none of the authors mentioned explains the distinction between mere promises of income redistribution and the promise to concede

\footnotetext{
${ }^{5}$ A significant example is provided by the history of Athens in the age of Solon and Pericles $\left(6^{\text {th }}\right.$ and $5^{\text {th }}$ century BC), when the citizenship rights were substantially extended to the lower classes in order to cope with the increasing need of military manpower for both the army (the hoplite phalanx) and the navy (e.g. Beukema, 1941, Dolman, 2004). Andreski (1968) discusses several other cases of expansion of political and social citizenship rights triggered by changes in the military technology toward the model of mass-army, such as China during the "warring kingdoms" period (480 to 221 BC) century, or the Roman Republic during the sixth century.

${ }^{6}$ Other scholars such as Hintze (1975), Tilly (1975, 1990), Skocpol (1979) and Kennedy (1987), also remark the importance of warfare as determinant of political development, but focus on other forms of institutional change, e.g. the expansion of "state capacity" (see Besley and Persson, 2007, for a recent investigation of this issue).
} 
democracy, which is instead addressed by our theory.

Our theory is closely related to a recent literature in political economy, which investigates the reasons why countries democratize, and more generally experience transitions across different political regimes and institutions. This literatures includes a number of contributions of Acemoglu and Robinson (2000, 2001 and 2006), who argue that the elite may transfer the political power to the masses in order to make a credible commitment to future income redistribution, which allows the prevention of social unrest and revolutions. A somehow similar explanation can be found in Conley and Temimi (2001). Lizzeri and Persico (2004) and Llavador and Oxoby (2005) offer another type of rationale for the extension of the franchise, based on an intra-elite conflict between landlords and commercial classes, rather than on a threat of revolution posed to the elite by the poor. Boix (2003) emphasizes the importance of economic fundamentals, such as asset specificity and income inequality, for the transition to democracy. Jack and Lagunoff (2006) and Gradstein (2007) propose models where the extension of franchise allows the current pivotal decision maker voter to make credible commitments to future policy choices. Glaeser (2006) and Jackson and Morelli (2007) address the question, specular to the one that motivates our paper, of how political regimes affect the incentives of incumbent governments to wage war, while Greif (2006) argues that internal rivalries within a polity may favor the endogenous emergence of political institutions suitable to regulate and prevent the outbreak of potential domestic conflicts.

The paper is organized as follows. Section 2 presents the baseline model. In Section 3, we define the equilibrium concept adopted and characterize the equilibrium of the model. Section 4 presents some historical evidence illustrating the causal mechanism driving democratization which our theory identifies. Section 5 concludes. Section 6 contains the proofs not reported in the text.

\section{The Basic Environment}

We consider an economy in discrete time, populated by a continuum of measure 1 of infinitely lived agents. All agents have the same risk-neutral preferences described by

$$
\mathbb{E}_{0} \sum_{t=0}^{\infty} \beta^{t}\left(c_{j, t}-e_{j, t} \eta\right),
$$

where $\mathbb{E}_{0}$ is the expected value operator at time $t=0, \beta \in(0,1)$ is the common discount factor, $c_{j, t}$ is the consumption of a private good of individual $j$ (which is always equal to disposable income), and $e_{j, t}$ is equal to one if individual $j$ undertakes at time $t$ an activity described below 
involving the utility $\operatorname{cost} \eta>0$, and equal to zero vice versa.

Agents differ in terms of their productivity or skills level, that can be high or low. The high-skill agents, forming a continuum of measure $n<1 / 2$, have a pre-tax income equal to $A^{H}$; the low-skill agents are a continuum of measure $1-n$ and have a pre-tax income equal to $A^{L}<A^{H}$. Because the high-skill agents are initially in control of the political system, we also refer to them as the elite, and to low-skill agents as the citizens. Moreover, we denote with $\mathcal{H}$ and $\mathcal{L}$ respectively, the set of high-skill and the set of low-skill agents.

The economy and the agents are part of a country which, at any point in time, can be either in war or in peace with an external enemy, as denoted by the state variable $\mu_{t}$. When $\mu_{t}=\mu^{w}$, the country is involved in a war at time $t$; when instead $\mu_{t} \in\left\{\mu^{u}, \mu^{p}\right\}$, the country is in peace, but it faces either one of two different levels of future external threat. In state $\mu_{t}=\mu^{u}$ (that we define as "unstable peace"), a war occurs in the following period with a relatively high probability, $q^{u} \in(0,1)$, and in state $\mu_{t}=\mu^{p}$ ("stable peace"), a war occurs in the following period with a relatively small probability, $q^{p} \in\left[0, q^{u}\right]$. Furthermore, we assume that the state $\mu^{u}$ obtains only after a period of war, and with probability one. More formally, the stochastic process governing the evolution of $\mu$ is such that: $\operatorname{Pr}\left\{\mu_{t+1}=\mu^{w} \mid \mu_{t}^{p}\right\} \equiv q^{p}$, $\operatorname{Pr}\left\{\mu_{t+1}=\mu^{p} \mid \mu_{t}^{p}\right\} \equiv 1-q^{p}, \operatorname{Pr}\left\{\mu_{t+1}=\mu^{w} \mid \mu_{t}^{u}\right\} \equiv q^{u}, \operatorname{Pr}\left\{\mu_{t+1}=\mu^{p} \mid \mu_{t}^{u}\right\}=1-q^{u}$, and $\operatorname{Pr}\left\{\mu_{t+1}=\mu^{u} \mid \mu_{t}^{w}\right\}=1$.

If a war occurs, the country wins it with probability $P_{t}$, which is endogenously determined in the equilibrium of the model. In particular, $P_{t}$ depends positively on the overall effort put by the citizens in fighting wars, reflecting the fact that the military technology adopted is based on the deployment of a mass-army, i.e. of a military organization that relies heavily on conscription and war effort of a large number of citizens-soldiers. ${ }^{7}$ To simplify the analysis, we assume that all and only the citizens join the army in periods of war, and that $P_{t} \in\{0,1\}$, i.e. a war is either won or lost with probability one. In particular, we assume that $P_{t}=1$ if the number of citizens who put the required effort in fighting (as explained below), is larger than some threshold $\lambda \leq 1-n$, and $P_{t}=0$ otherwise. $^{8}$ If a war is ever lost, the external enemy permanently takes the country over from the following period, and all agents receive a constant payoff equal to a fraction $(1-\phi)$ of the output they produce from then on. The exogenous parameter $\phi \in(0,1)$, i.e. the share of income permanently lost in favor of the enemy in case

\footnotetext{
${ }^{7}$ The concept of "military effort" should here be understood in a broad sense, including obviously the effort put by the soldiers on the battlefield, but also the effort put by the women mobilized to serve in the home front, e.g. substituting the conscripted men in factory jobs and in other tasks.

${ }^{8}$ Given that all poor are identical, in equilibrium either all or none of them will put effort, so that the particular value of $\lambda$ is irrelevant.
} 
of defeat, captures the extent of the external threat faced.

Putting effort in fighting entails a utility cost $\eta$ equal for all citizens, but the corresponding individual decision is imperfectly observable to the state; specifically, "shirking" is detected with probability $\alpha<1$. This generates a moral hazard problem, whereby citizens-soldiers can be induced to put effort only if they are paid some informational rent, i.e. receive some benefit in excess of the effort cost $\eta$, which is potentially lost in case of detected misbehavior. In particular, we assume that if a citizen-soldier is caught shirking at period $t$, he is permanently excluded from any fiscal redistribution provided by the government since period $t+1 .^{9}$ The individual effort decision at time $t$ of citizen $j$ is denoted as $e_{j, t} \in\{0,1\}$.

The government in office can tax and redistribute income. The instrument available to raise taxes is proportional taxation at rate $\tau_{t}$, and the revenues collected are rebated with a uniform fiscal transfer $T_{t}$. This fiscal transfer is provided to all and only the agents who have never been caught shirking up to period $t$, and we assume that, if an agent is caught shirking at period $t$ or before, his transfer is thrown away by the government. ${ }^{10}$ The government budget needs to be always balanced, and this implies that

$$
T_{t} \leq \tau_{t} \bar{y}
$$

where $\bar{y}=(1-n) A^{L}+n A^{H}$ denotes the aggregate (and average) level of output. At any period $t$ such that the country has never been defeated in a war, the post-tax income of an individual $j$ is equal to

$$
a_{t}^{j}=\left(1-\tau_{t}\right) A^{H}+T_{t}
$$

if $j \in \mathcal{H}$, and equal to

$$
a_{t}^{j}=\left(1-\tau_{t}\right) A^{L}+T_{t}
$$

if $j \in \mathcal{L}$ and he has not been caught shirking up to period $t$ included. Finally, if $j \in \mathcal{L}$, and the individual has been caught shirking before period $t$, his net income at period $t$ is equal to

$$
\hat{a}_{t}^{j}=\left(1-\tau_{t}\right) A^{L}
$$

We assume that taxation generates no distortions as long as $\tau$ is smaller than some threshold $\hat{\tau} \in(0,1)$, and there are exceedingly large distortions if $\tau$ is set anywhere above $\hat{\tau}$. This implies that the set of feasible taxes is $[0, \hat{\tau}]$.

\footnotetext{
${ }^{9}$ As explained in more details below, this comes from the fact that fiscal policy is implemented before citizens make their effort decision.

${ }^{10}$ This assumption is unimportant since all citizens always put effort in fighting in any equilibrium where some income is redistributed.
} 
We consider a dynamic political game involving the elite and the citizens, who make their decisions facing the threat posed by an external enemy. Given the policy instrument specified below, there is no conflict of interest within the elite, and within the two subgroups in with the low-skill agents may potentially be divided, i.e. those who have never been caught shirking, and those who have been caught shirking. Therefore, we can assume that, if any group has political power, the relevant political decisions made in each period reflect the preferences of the representative agent of that group. In each period of war, the citizens also make individually an economic choice, i.e. whether to put effort or not in fighting, after the government has made all relevant political decisions for that period. Moreover, in making their effort decision, the citizens behave competitively, in the sense that each of them assumes that his action affects neither future government policies nor the effort decisions of other agents. ${ }^{11}$

The game considered has two types of state variables. In particular, there are two aggregate state variables $s_{t} \in \mathcal{S} \equiv\{N, D, C\}$ and $\mu_{t} \in \Delta \equiv\left\{\mu^{w}, \mu^{p}, \mu^{u}\right\}$, denoting respectively the political regime in place at the beginning of period $t$, and whether the country is in war or in peace (which may be stable or unstable) at the same time, and an individual state variable $z^{j, t-1} \in\{0,1\}$, with $z^{j, t-1}=0$ denoting a citizen $j$ that has never been caught shirking up to period $t-1$, and vice versa. The political regime of the country at the beginning in period $t$ can be an oligarchy $\left(s_{t}=N\right)$, where the elite have all political power, a democracy $\left(s_{t}=D\right)$, where a leader (the representative member of one the existing social groups) is elected by majority voting and implements his preferred policy, ${ }^{12}$ or the regime that emerges after a military defeat $\left(s_{t}=C\right)$, where neither the elite nor the citizens have any power and the corresponding above-described policy is implemented forever. Since the political state at period $t$ may change endogenously, we let $s_{t}^{\prime}$ denote the political state obtaining if there is a regime transition at $t$, which is also equal to the political state $s_{t+1}$ obtaining at the beginning of period $t+1$. Finally, the long run (endogenous) political regime of the model will be denoted by $s^{\infty}$.

All political decisions in each period $t$ are taken at the beginning of the period, after observing the realization of $\mu_{t}$, and before the citizens make their effort decision when $\mu_{t}=\mu^{w}$.

\footnotetext{
${ }^{11}$ The political game that we consider has many feature in common with the framework proposed by Chari and Kehoe (1990). They study a model where a benevolent government chooses policy sequentially in presence of a large number of agents. While individuals behave competitively, the government is strategic in that it takes into account the consequence of its actions on the future decisions of private agents. In this setup, Chari and Kehoe prove the existence of trigger-type equilibria based on a reputational mechanism similar to the one operating in our model.

${ }^{12}$ The assumptions made on the democratic political process could be given a microfoundation assuming a citizen-candidate type of model of electoral competition. In practice, because in equilibrium one group (the citizens who have never been caught shirking) will always make up for more than $50 \%$ of the voters in democracy, the particular way the political process is modelled is unimportant.
} 
The policy decisions include the tax rate $\tau_{t} \in[0,1]$, the level of the fiscal transfer $T_{t} \geq 0$, and the decisions to promise or not and to concede or not democracy, denoted respectively by $\rho_{t} \in\{0,1\}$ and $\psi_{t} \in\{0,1\}$. Moreover, in state $\mu^{w}$ no political transitions are possible by assumption, and therefore only the promise to concede democracy in the following period (unstable peace) can be made. In particular, if the oligarchy chooses $\rho_{t-1}=1$ and $\psi_{t}=1$ (i.e. the elite promise democracy at period $t-1$, and implements the promise at period $t$ ), a transition to democracy occurs at the beginning of period $t$ and becomes immediately effective. If the elite give up political power by conceding democracy at some point, it has no chance of getting it back (e.g. by organizing a military coup against democracy).

Unlike the citizens, who have pre-tax income below average and may gain from some fiscal redistribution of income financed with linear taxation (see Section 3.2), the elite are armed by taxation per se. Nonetheless, even an oligarchy may want to commit to implement some income redistribution in order to provide to the citizens the incentive to fight hard in war times, thus preventing a military defeat and the consequent income loss. Because the external threat is not always present, the elite may not be able to commit to a sufficiently large intertemporal income redistribution, due to the incentive of deviating from such a promise in peace times. This incentive is clearly potentially stronger in the state of stable peace $\mu^{s}$, as the likelihood of occurrence of a war in the future is lower than in state $\mu^{u}$, and therefore the punishment of a deviation is expected to be less severe. If this is the case, the only way the elite may be able to provide the due incentives to the citizens-soldiers to fight well in a war, is to promise to concede democracy at the end of the war. Conceding democracy is a form of credible commitment to future redistribution since it involves a permanent reallocation of political power to the citizens. Moreover, because a transition to democracy can happen in the following a period of war, i.e. in a state of unstable peace where the country faces a relatively serious potential external threat, the promise to conceding democracy needs to be ex post optimal for the elite in state $\mu^{u}$ only.

Summarizing, the sequence of events taking place within the stage-game is the following.

1. The realization of the state variable $\mu_{t}$ is publicly revealed.

2. If $s_{t}=N$ and $\mu_{t} \neq \mu^{w}$, the oligarchy chooses $\psi_{t}$. If $\psi_{t}=0$, then $s_{t}^{\prime}=s_{t+1}=N$, and if $\psi_{t}=1$, then $s_{t}^{\prime}=s_{t+1}=D$.

3. If $s_{t}=N$, the oligarchy chooses $\rho_{t}$ and a fiscal policy vector $\left\{\tau_{t}^{N}, T_{t}^{N}\right\}$. If $s_{t}=D$, democracy chooses a fiscal policy vector $\left\{\tau_{t}^{D}, T_{t}^{D}\right\}$. 
4. If $\mu_{t}=\mu^{p}$, the fiscal policy announced by the government at the beginning of period $t$ is implemented.

5. If $\mu_{t}=\mu^{w}$, then:

a) Each citizen $j$ decides his war effort level $e_{j, t}$, the war is fought and its outcome is publicly revealed.

b) The fiscal policy announced by the government at the beginning of period $t$ is implemented, and a fraction $\alpha$ of the citizens-soldiers with $z^{j, t-1}=1$, choosing $e_{j, t}=0$, are detected.

c) If the war is won the government remains in power and $s_{t+1}=s_{t}$. If the war is lost, the country is taken over permanently by the external enemy and $s_{t+r}=C$ for all $r \geq 1$.

Finally, we assume that the society starts with an oligarchic political regime, i.e. $s_{0}=N$.

\section{Definition of the Equilibrium}

The history of the game includes both individual and aggregate outcomes. Individual outcomes potentially include the list of all past effort decisions of a citizen, and whether a citizen has ever been caught shirking or not in the past. In practice, the only relevant information of each citizen's history is whether or not he has been ever caught shirking, i.e. $z^{j, t-1} \in\{0,1\}$. The aggregate outcomes include the list of all past political decisions (i.e. the levels of taxes and transfers), which is observed by all agents. We denote with $h^{t}$ the aggregate "political" history of the game up to time $t$, and with $H^{t}$ the set of all such histories.

Strategies assign actions for any history in $H^{t} \times\{0,1\}$. A strategy profile the players in the game can be represented by a mapping ${ }^{13}$

$$
\sigma: H^{t} \times\{0,1\} \rightarrow\{0,1\} \times[0,1] \times \mathbb{R}_{+}^{2} \times\{0,1\}^{2}
$$

where the range of the strategy profiles again refers to the individual effort decision $e_{j, t} \in\{0,1\}$ when $j \in \mathcal{L}$, and to the choice of the tax rate $\tau_{t} \in[0,1]$, of the level of the fiscal transfer $T_{t} \in \mathbb{R}_{+}$,

\footnotetext{
${ }^{13}$ The government in office, unlike individual citizens, also observes which citizens have been ever caught shirking. However, it turns out that this information does not affect the strategy of the government. The reason is that, if a set of zero measure of citizens deviates, this has no effect on the strategy of the government by the competitive assumption. If instead a set of positive measure of citizens deviates, a transition to state $C$ obtains in the period that follows. Because state $C$ is absorbing, we do not need to specify how any government plays after any history where a transition to $C$ has occurred.
} 
and to the decision of whether promise democracy, $\rho_{t} \in\{0,1\}$, and to concede democracy, $\psi_{t} \in\{0,1\}$, when $j$ is the leader making political decisions. A strategy profile $\sigma^{*}$ is a subgame perfect equilibrium (SPE) if it is a best response to itself for all $\left(h^{t}, z^{j, t-1}\right) \in H^{t} \times\{0,1\}$ (i.e., if it is sequentially rational). ${ }^{14}$

In the following, rather than offering a complete characterization of the set of the SPEs of the game, which is potentially very large, we will focus the attention on the equilibrium that is best for the elite, i.e. where the elite's value (namely the present discounted value of their payoffs) is maximized. In the SPE in question, the elite are able to induce the citizens to fight hard while retaining political power for the largest possible set of parameters values, and thus the scope for wars to induce democratic transitions is as limited as possible.

As already explained, we do not restrict strategies to be Markovian (i.e. to depend on payoff relevant information only). This is because in a Markovian subgame perfect equilibrium, it would never be optimal for the elite to concede democracy in peace times, and political institutions cannot be changed in war times by assumption in our model. As a result, a transition to democracy would never occur in a Markov perfect equilibrium. Vice versa, in our model a transition to democracy can occur since players follow history-dependent strategies, which may allow the elite to make, in a period of war, the credible promise to concede democracy in the following period of peace.

\subsection{The Effort Decision of the Citizens}

In this subsection, we begin the analysis of the political game by analyzing the effort decision of the citizens. In particular, we seek to characterize the incentive-compatibility constraint that needs to be satisfied in order to induce each citizen to put effort in fighting wars.

Consider the subgame played after any history $h^{t-1}$ such that $s_{t} \in\{R, D\}$, i.e. a military defeat has never occurred. If $\mu_{t}=\mu^{w}$ and $z^{j, t-1}=0$ (i.e. if citizen $j$ has never been caught shirking up to period $t-1$ ), sequential rationality implies that citizen $j$ chooses $e_{j, t}=1$ rather than $e_{j, t}=0$ provided that

$$
V^{L}\left(s_{t}, \mu^{w} \mid e_{j, t}=1\right) \geq V^{L}\left(s_{t}, \mu^{w} \mid e_{j, t}=0\right)
$$

The left-hand-side of this inequality, $V^{L}\left(s_{t}, \mu^{w} \mid e_{j, t}=1\right)$, is the value of citizen $j$ corresponding to $e_{j, t}=1$. Under the assumption that $P_{t}=1$ (i.e. a continuum of citizens larger or equal

\footnotetext{
${ }^{14}$ We will often refer to subcomponents of $\sigma$ rather than the entire strategy profile and, when there is no risk of confusion, and we will use the index $j$ to denote individuals or groups interchangeably.
} 
than $\lambda$ chooses to put effort in fighting at period $t$ ), this value satisfies the following recursion

$$
V^{L}\left(s_{t}, \mu^{w} \mid e_{j, t}=1\right)=\left(1-\tau_{t}\right) A^{H}+T_{t}-\eta+\beta V^{L}\left(s_{t+1}, \mu^{u}\right)
$$

This expression decomposes the value in question into the flow payoff, which includes the post-tax and transfer income of citizen $j$ net of the utility cost of effort $\eta$, and the discounted continuation value $V^{L}\left(s_{t+1}, \mu^{u}\right)$. The latter value reflects the fact that in the equilibrium under consideration $P_{t}=1$, and this implies that $s_{t}$ and $s_{t+1}$ are both different from $C$. This value also takes into account that periods of war are followed by periods of unstable peace. In particular, the values of citizen $j$ in state $\left(s_{t}, \mu^{u}\right)$ and $\left(s_{t}, \mu^{p}\right)$ are respectively

$$
V^{L}\left(s_{t}, \mu^{u}\right)=\left(1-\tau_{t}\right) A^{H}+T_{t}+\beta\left[q^{u} V^{L}\left(s_{t+1}, \mu^{w}\right)+\left(1-q^{u}\right) V^{L}\left(s_{t+1}, \mu^{p}\right)\right]
$$

and

$$
V^{L}\left(s_{t}, \mu^{p}\right)=\left(1-\tau_{t}\right) A^{H}+T_{t}+\beta\left[q^{p} V^{L}\left(s_{t+1}, \mu^{w}\right)+\left(1-q^{p}\right) V^{L}\left(s_{t+1}, \mu^{p}\right)\right] .
$$

Equations (7), (8) and (9) represents the system of recursions satisfied by the values of citizen $j$ in the three possible states of the world, under the hypotheses stated above.

If instead citizen $j$ chooses $e_{j, t}=0$, his value is equal to

$$
V^{L}\left(s_{t}, \mu^{w} \mid e_{j, t}=0\right)=\left(1-\tau_{t}\right) A^{H}+T_{t}+\beta\left[(1-\alpha) V^{L}\left(s_{t+1}, \mu^{u}\right)+\alpha \hat{V}^{L}\left(s_{t+1}, \mu^{u}\right)\right] .
$$

The first term in the recursion (10) is the flow payoff of agent $j$ if $e_{j, t}=0$, and reflects the fact that the agent "saves" the effort cost $\eta$ but loses the fiscal transfers granted since period $t+1$ if caught shirking, which happens with probability $\alpha$. The second term in square brackets is the continuation value of $j$, and it also reflects the fact that, with probability $\alpha$ the shirking of agent $j$ at period $t$ is detected, in which case $z^{j, t}=1$ and he gets a value $\hat{V}^{L}\left(s_{t+1}, \mu^{u}\right)$, characterized below, since period $t+1$. Note also that the notation used accounts for the possibility that a political transition may occur between period $t$ and period $t+1$, i.e. $s_{t} \neq s_{t+1}$.

Because a citizen caught shirking will never put effort in fighting wars (since putting effort would only entail the utility cost $\eta$ at no gain), the value $\hat{V}^{L}\left(s_{t+1}, \mu^{u}\right)$ can be decomposed as the discounted sum of the stream of future post-tax incomes of the agent beginning since period $t+1$, or

$$
\hat{V}^{L}\left(s_{t+1}, \mu^{u}\right)=\sum_{v=1}^{\infty} \beta^{v-1}\left[\left(1-\chi_{t+v}\right) A^{L}\right] .
$$

In this expression, $\chi_{t+v}$ denotes the wedge between the income produced and consumed by an agent $j$ with $z^{j, t+v-1}=1$, and which is equal to $\tau_{t+v}$ if $s_{t+v} \in\{D, N\}$ and to $\phi$ if $s_{t+v}=C$. 
Using (7) and (10), constraint (6) can be written in the more explicit form ${ }^{15}$

$$
\alpha \beta\left[V^{L}\left(s_{t+1}, \mu^{u}\right)-\hat{V}^{L}\left(s_{t+1}, \mu^{u}\right)\right] \geq \eta .
$$

If the incentive-compatibility constraint (12) is satisfied, the best response of citizen $j$ to any strategy profile such that $P_{t}=1$ is to choose $e_{j, t}=1$. The model has yet potentially another equilibrium where a "coordination failure" occurs, as a result of the fact that no citizen chooses to put effort, if he expects any other citizen to do the same thing (and where $P_{t}=0$ as a result). However, because we are restricting the attention to the best SPE for the elite, in the following we will neglect the equilibrium featuring this kind of coordination failure, and assume that if constraint (12) is satisfied, then the equilibrium where all citizens choose $e_{j, t}=1$ obtains. ${ }^{16}$

In the following we will also assume (without making explicit restrictions) that the parameters of the model are such that condition (12) is satisfied if $T_{t+v}=\hat{\tau} \bar{y}$ for each $v \geq 1$, i.e. when the maximum possible fiscal transfer is granted at each period of time by the government in power. $^{17}$

\subsection{Values in Democracy}

In this section, we characterize the SPE of the subgames beginning with democracy in power $\left(s_{t}=D\right)$. As explained before, decisions in democracy are made by majority voting. Because the citizens who are detected shirking in war times lose forever any fiscal transfer conceded by the government, there are potentially three distinct social groups, i.e. the elite, and the citizens who have and who have not ever been caught shirking respectively. This makes the characterization of the political equilibrium under majority voting potentially non trivial. However, it will be true in equilibrium that if $s_{t}=D$, then $\hat{\mathcal{L}}_{t}=\varnothing$, where $\hat{\mathcal{L}}_{t}$ denotes the set of lowskill agents who have ever been caught shirking before period $t .^{18}$ The following proposition characterizes the SPE of a subgame beginning in democracy.

Proposition 1 The unique SPE of all subgames starting with $s_{t}=D$, and $\hat{\mathcal{L}}_{t}=\varnothing$ involves $\left(\tau_{t} \equiv \tau^{D}=\hat{\tau}, T_{t} \equiv T^{D}=\hat{\tau} Y\right)$ and $e_{j, t}=1$ for each date $t$ and for each $j \in \mathcal{L}$. Moreover, $P_{t}=1$ for any date $t$ such that $\mu_{t}=\mu^{w}$, and democracy is an endogenously absorbing state.

\footnotetext{
${ }^{15}$ Note that the fiscal transfer $T_{t}$ does not appear in (12), since it is provided to agent $j$ before he makes his effort decison. Since agent $j$ obtains $T_{t}$ irrespectively on his choice of effort level, $T_{t}$ has no influence on his decision.

${ }^{16}$ In practice, the potential coordination failure in question could be overcome due to the actions of leaders, political parties, and other organizations pursuing the collective interests of the citizens.

${ }^{17}$ It was not the case, then no scope for political or economic concessions would exist, and the model's unique equilibrium would involve a transition to state $C$ after the first period of war.

${ }^{18}$ Intuitively, democracy is conceded by the elite precisely to induce the citizens to put effort in fighting wars. Moreover, since all citizens are ex ante equal, they all make the same effort decision in equilibrium. This implies that, if democracy is ever conceded, all citizens always choose to put effort in fighting wars.
} 
Proof. Suppose first that $\mu_{t} \neq \mu^{w}$. Because democracy persists until a military defeat occurs, the continuation value of an agent since period $t+1$ is not influenced by the policy chosen at period $t$. It follows that the fiscal policy chosen by the representative agent, assuming that $\hat{\mathcal{L}}_{t}=\varnothing$, is the policy maximizing his per period utility, namely the solution of the following program

$$
\begin{aligned}
& u^{L}(D) \equiv \max _{\tau \in[0, \hat{\tau}], T \in \mathbb{R}_{+}}(1-\tau) A^{L}+T \\
& \text { subject to } T \leq \tau Y
\end{aligned}
$$

Clearly, the government budget constraint must always be binding. Otherwise, it would be possible to increase $u^{L}(D)$ either by reducing $\tau$ or by increasing $T$. Substituting $T=\tau Y$ into the objective function of the program yields a function which is strictly increasing in $\tau$, and thus maximized at $\tau=\hat{\tau}$.

Suppose now that $\mu_{t}=\mu^{w}$. If the fiscal policy involving $\tau=\hat{\tau}$ and $T=\hat{\tau} Y$ is implemented also in state $\mu^{w}$, all citizens-soldiers $j \in \mathcal{L}$ choose $e_{j, t}=1$, which ensures that $P_{t}=1$. This clearly gives the citizens a value strictly greater than the value that they can get by choosing a fiscal policy with $\tau_{t}<\hat{\tau}$, that either leads to $P_{t}=0$ ( since $e_{j, t}=0$ ), and gives the citizens a per period payoff of $(1-\phi) A^{L}$ forever, or also leads to $P_{t}=1$, but fails to maximize their per period utility.

\subsection{Values in Oligarchy}

In this subsection, we consider the subgames beginning in state $N$ (oligarchic political regime), and characterize the payoffs of the elite depending on the different possible strategies that the oligarchy can follow. When in power in the state of war $\mu^{w}$, the oligarchy has three strategies to choose from:

1. Make no political or economic concession to the citizens (i.e., "no action," or $\mathcal{N} \mathcal{A}$ ).

2. Promise to the citizens to concede democracy after a war (i.e., "democratization," or $\mathcal{D}$ ).

3. Promise to the citizens some incentive-compatible intertemporal redistribution of income only (i.e., "redistribution," or $\mathcal{R}$ ).

The first possible strategy of the elite, no-action $(\mathcal{N} \mathcal{A})$, involves no promise of concessions to the citizens and leads to a permanent transition to the absorbing state $C$ after one period. Since in state $C$ all agents consume only the fraction $(1-\phi)$ of their income that is not 
confiscated, the value that the elite obtain in state $\mu^{w}$, when they choose $\mathcal{N} \mathcal{A}$, is equal to sum of their full per period income, plus the present discounted value of their net future income, or

$$
V^{H}\left(N, \mu^{w} \mid \text { no action }\right)=A^{H}+\beta \frac{(1-\phi) A^{H}}{1-\beta} .
$$

Next, we can compute the value of the elite when they promise in state $\mu^{w}$ to concede democracy in the forthcoming state $\mu^{u}$. Using equation (2) and Proposition 1, we have that the value of the elite beginning in state $s_{t}=D$ reads

$$
V^{H}(D)=\frac{(1-\hat{\tau}) A^{H}+\hat{\tau} Y}{1-\beta} .
$$

Because the concession of democracy leads immediately to a political transition, (15) also expresses the value of the elite when they concede democracy in state $\mu^{u}$. Finally, the value of the elite, beginning in state $\mu^{w}$, when they credibly promise to concede democracy in the following period reads

$$
V^{H}\left(N, \mu^{w} \mid \text { democracy }\right)=A^{H}+\beta \frac{(1-\hat{\tau}) A^{H}+\hat{\tau} Y}{1-\beta} .
$$

This expression reflects the fact that if $\mathcal{D}$ is chosen in state $\mu^{w}$, the current war is won with probability one because the citizens put effort, and the elite retain their full income today, but a permanent transition to democracy (with the corresponding fiscal policy outcome) follows from tomorrow.

The promise made in war time to concede democracy after the end of the war is credible only if conceding democracy is optimal for the elite in the subgame beginning in state $\mu^{u}$, which depends on how the citizens will react to a deviation of the elite from the promise of democracy. We assume that citizens inflict on the elite the worst possible (credible) punishment, consisting in not putting effort in the next war (i.e., $e_{j, t}=0$ for all $j$ ), after observing any public history $h^{t-1} \neq \hat{h}^{t-1}$, where $\hat{h}^{t-1}$ is the equilibrium history induced by the strategy $\mathcal{D}$. This implies that a deviation from strategy $\mathcal{D}$ triggers a permanent transition to state $C$ as soon as state $\mu^{w}$ obtains. This in turn implies that the best strategy for the elite after any history $h^{t-1} \neq \hat{h}^{t-1}$ is clearly to set $\tau_{t}=0$.

The values for the elite of a deviation from a promise of democracy in state $\mu^{u}, \mu^{p}$ and $\mu^{w}$ defined respectively as $\tilde{V}^{H}\left(N, \mu^{u}\right), \tilde{V}^{H}\left(N, \mu^{p}\right)$ and $\tilde{V}^{H}\left(N, \mu^{w}\right)$, can be computed as the solution of the following system of recursive equations

$$
\begin{aligned}
& \tilde{V}^{H}\left(N, \mu^{u}\right)=A^{H}+\beta\left[q^{u} \tilde{V}^{H}\left(N, \mu^{w}\right)+\left(1-q^{u}\right) \tilde{V}^{H}\left(N, \mu^{p}\right)\right], \\
& \tilde{V}^{H}\left(N, \mu^{p}\right)=A^{H}+\beta\left[q^{p} \tilde{V}^{H}\left(N, \mu^{w}\right)+\left(1-q^{p}\right) \tilde{V}^{H}\left(N, \mu^{p}\right)\right],
\end{aligned}
$$


and

$$
\tilde{V}^{H}\left(N, \mu^{w}\right)=A^{H}+\beta \frac{(1-\phi) A^{H}}{1-\beta} .
$$

These expressions reflect the fact that the most profitable deviation for the elite involves setting taxes equal to zero in any state of the world, so the elite retain their full income as long as $s$ $\neq C$.

Remark 1 It can be verified that $\tilde{V}^{H}\left(N, \mu^{w}\right)<\tilde{V}^{H}\left(N, \mu^{u}\right)<\tilde{V}^{H}\left(N, \mu^{p}\right)$. This result is intuitive since the flow payoff of the elite in state $\mu^{u}$ and $\mu^{p}$ is equal to $A^{H}$ whereas the flow payoff of the elite in state $\mu^{w}$ is equal to $A^{H}$ for one period and permanently equal to $(1-\phi) A^{H}$ since the following period. Hence, the value of the elite is the lowest in state $\mu^{w}$. Furthermore, the punishment of a deviation in a period of unstable peace is expected to come sooner than in stable peace ( since $\left.q^{u}>q^{s}\right)$, which implies that $\tilde{V}^{H}\left(N, \mu^{u}\right)<\tilde{V}^{H}\left(N, \mu^{p}\right)$.

By the one-stage deviation principle (Fudenberg and Tirole, 1991), a necessary and sufficient condition for subgame perfection is that the value of conceding democracy in state $\mu^{u}$ for the elite is larger than the value of deviating from the corresponding promise, given the strategy of the citizens and the subsequent strategy of the elite. This leads to the following no-deviation condition of the elite from the war time promise to concede democracy after the end of the war

$$
V^{H}(D) \geq \tilde{V}^{H}\left(N, \mu^{u}\right),
$$

where $V^{H}(D)$ and $\tilde{V}^{H}\left(N, \mu^{u}\right)$ are defined respectively by (15) and recursively by (17), (18) and (19).

Lemma $1 \exists \phi=\phi^{*} \in(0,1]$ such that the promise made in state $\mu^{w}$ to concede democracy in the subsequent state $\mu^{u}$ is credible if and only if $\phi \geq \phi^{*}$.

Proof. We begin by observing that the system of recursions (17), (18) and (19), satisfied by the values for the elite of a deviation from a promise of conceding democracy in state $\mu^{u}$, $\mu^{p}$ and $\mu^{w}$ has solution ${ }^{19}$

$$
\begin{gathered}
\tilde{V}^{H}\left(N, \mu^{u}\right)=A^{H}+\frac{\beta}{1-\beta}\left[q^{u}(1-\phi)+\left(1-q^{u}\right) \frac{1-\beta+\beta q^{p}(1-\phi)}{1-\beta\left(1-q^{p}\right)}\right] A^{H}, \\
\tilde{V}^{H}\left(N, \mu^{p}\right)=\frac{(1-\beta) A^{H}+\beta q^{p}(1-\phi) A^{H}}{(1-\beta)\left[1-\beta\left(1-q^{p}\right)\right]},
\end{gathered}
$$

\footnotetext{
${ }^{19}$ It is straightforward to verify that $\tilde{V}^{H}\left(N, \mu^{w}\right)<\tilde{V}^{H}\left(N, \mu^{u}\right)<\tilde{V}^{H}\left(N, \mu^{p}\right)$, as pointed in Remark 1.
} 


$$
\tilde{V}^{H}\left(N, \mu^{w}\right)=A^{H}+\beta \frac{(1-\phi) A^{H}}{1-\beta} .
$$

The strategy $\mathcal{D}$, i.e. setting $\rho_{t}=1$ and $\psi_{t+1}=1$ if $\mu_{t}=\mu^{w}$, is credible for the elite if condition (20) holds. This condition can be expressed in terms of the parameter $\phi$. From (21), it is clear that $\tilde{V}^{H}\left(N, \mu^{u}\right)$ is a continuous and strictly decreasing function of $\phi$, so that we denote it as $\tilde{V}^{H}\left(N, \mu^{u} \mid \phi\right)$, and such that $\tilde{V}^{H}\left(N, \mu^{u} \mid \phi=0\right)=A^{H} /(1-\beta)>V^{H}(D)$. By Proposition $1, V^{H}(D)$ does not depend on $\phi$ (since the transition to democracy is sufficient to prevent a military defeat at any future period). It follows that the equation

$$
\tilde{V}^{H}\left(N, \mu^{u} \mid \phi\right)=V^{H}(D)
$$

has at most one solution over the interval $(0,1)$, and we define $\phi^{*}$ as the value of $\phi$ that satisfies this equation. If equation (24) has no solution in $(0,1)$, i.e. $\tilde{V}^{H}\left(N, \mu^{u} \mid \phi\right)>V^{H}(D)$ for all possible values of $\phi$, this means that democracy can never be credibly promised and we conventionally set $\phi^{*}=1$, as stated in the main text, and we conventionally set $\phi^{*}=1$.

Lemma 1 shows that democracy can be credibly promised only if the cost of a military defeat, parametrized by $\phi$, is sufficiently large. For future reference, it is useful to point out that the threshold $\phi^{*}$ does not depend on $\eta$ as this parameter does not appear on either side of equation (24). Moreover, from Lemma 1 and from the ranking of the deviation payoffs established in Remark 1, it follows that the elite prefer the strategy "democracy" to the strategy "no-action," whenever the former is feasible. This is states and proved in the following lemma.

Lemma 2 If $\phi \geq \phi^{*}$, strategy $\mathcal{D}$ is both feasible and gives the elite a higher equilibrium value than strategy $\mathcal{N} \mathcal{A}$.

Proof. We need to show that $V^{H}\left(N, \mu^{w} \mid\right.$ democracy $)>V^{H}\left(N, \mu^{w} \mid\right.$ no action $)$ when $\phi \geq \phi^{*}$ and, therefore, strategy $\mathcal{D}$ is feasible. This comes from the following facts: $a$ ) $V^{H}\left(N, \mu^{w} \mid\right.$ democracy $)>V^{H}(D)$ from the comparison of $(15)$ and $\left.(16) ; b\right) V^{H}(D) \geq \tilde{V}^{H}\left(N, \mu^{u}\right)$ when $\phi \geq \phi^{*}$ from Lemma $\left.1 ; c\right) \tilde{V}^{H}\left(N, \mu^{u}\right)>\tilde{V}^{H}\left(N, \mu^{w}\right)$ from Remark $\left.1 ; d\right) \tilde{V}^{H}\left(N, \mu^{w}\right)=$ $V^{H}\left(N, \mu^{w} \mid\right.$ no action $)$ from (23) and (14).

The last possible strategy of the elite consists in credibly promising a sufficiently generous income redistribution to the citizens that satisfies their incentive-compatibility constraint (12). To characterize strategy $\mathcal{R}$, we first write down the system of recursions satisfied by the values of the elite when they commit to an incentive-compatible redistribution in every possible state $\mu^{i} \in \Delta \equiv\left\{\mu^{w}, \mu^{u}, \mu^{p}\right\}$.

Defining $\left(\tau^{u}, T^{u}\right),\left(\tau^{p}, T^{p}\right)$ and $\left(\tau^{w}, T^{w}\right)$ as the vectors of taxes and transfers applying in the corresponding stationary SPE in periods of unstable peace, stable peace and war respectively, 
the values of the elite in these states can be characterized as the solution of the following system of recursive equations

$$
\begin{gathered}
V^{H}\left(N, \mu^{u}\right)=\left(1-\tau^{u}\right) A^{H}+T^{u}+\beta\left[q^{u} V^{H}\left(N, \mu^{w}\right)+\left(1-q^{u}\right) V^{H}\left(N, \mu^{p}\right)\right], \\
V^{H}\left(N, \mu^{p}\right)=\left(1-\tau^{p}\right) A^{H}+T^{p}+\beta\left[q^{p} V^{H}\left(N, \mu^{w}\right)+\left(1-q^{p}\right) V^{H}\left(N, \mu^{p}\right)\right], \\
V^{H}\left(N, \mu^{w}\right)=\left(1-\tau^{w}\right) A^{H}+T^{w}+\beta V^{H}\left(N, \mu^{u}\right),
\end{gathered}
$$

where we have decomposed the values of the elite in oligarchy in the three possible states of the world into the flow payoff and the discounted expected continuation value.

We use the one-stage deviation principle (Fudenberg and Tirole, 1991) to determine under what conditions no profitable deviations exist for the elite from the SPE with income redistribution (strategy $\mathcal{R}$ ). The value of the elite from a deviation depends naturally on the response of the citizens. The most severe credible punishment that a citizen can inflict on the elite consists in the threat of not putting effort in war in the future. This strategy implies that a military defeat (i.e., $P=0$ ) obtains as soon as a state of war occurs, leading immediately to the absorbing state where all agents retain and consume only a fraction $(1-\phi)$ of their earnings forever. Thus, we suppose that each citizen chooses not to put effort again (i.e. chooses $e_{j, t}=0$ ), after observing any public history $h^{t-1} \neq \tilde{h}^{t-1}$, where $\tilde{h}^{t-1}$ is the equilibrium history induced by the strategy $\mathcal{R}$. Taking the response of the citizens into account, the most profitable deviation for the elite involves implementing their ideal fiscal policy $\left(\tau^{N}=0\right)$ after any history $h^{t-1} \neq \tilde{h}^{t-1}$.

It follows that the value of the elite in state $\mu^{i} \in \Delta$ after a deviation from a promise of redistribution is equal to their value in the same state after a deviation from a promise of democratization, $\tilde{V}^{H}\left(N, \mu^{i}\right)$, expressed by the solution of the system of recursions (17), (18) and (19). Thus, the three no-deviation conditions of the elite applying in a SPE where the elite choose strategy $\mathcal{R}$ can be written compactly as

$$
V^{H}\left(N, \mu^{i}\right) \geq \tilde{V}^{H}\left(N, \mu^{i}\right)
$$

for every $\mu^{i} \in \Delta$.

We can now characterize the value of the elite in the subgame perfect equilibrium with redistribution that is best for the elite itself, beginning in the first period where a state of war occurs. In equilibrium, the elite commits to the vector of taxes $\left[\tau^{w}, \tau^{u}, \tau^{p}\right]$ subject to the constraint of providing the due incentives to the citizens. Let $T \equiv \inf \left\{t: \mu_{t}=\mu^{w}\right\}$ denote the first period of time when a state of war occurs. Because citizen-soldiers who are caught 
shirking at a point in time lose forever any fiscal transfer provided from the following period, the fiscal transfer provided in period $T$ by the elite does not influence the effort decision of the citizens-soldiers in $T$. Hence, the elite optimally set taxes at zero in period $T$ and commit to implement in the future the three state-dependent taxes solving the following program

$$
V^{H}\left(N, \mu^{w} \mid \text { redistribution }\right)=\max _{\tau^{w}, \tau^{u}, \tau^{p}} A^{H}+\beta V^{H}\left(N, \mu^{u},\left[\tau^{w}, \tau^{u}, \tau^{p}\right]\right),
$$

subject to the incentive-compatibility constraint of the citizen-soldiers (12), and to the three no-deviation conditions of the elite applying in the three possible states of the world, expressed by (28) for every $\mu^{i} \in \Delta$. Expression (29) reflects the fact that the elite retain their full income in $T$ and commit to a stationary vector of taxes since period $T+1$.

If the constraint set defined by the four inequalities (12) and (28) for every $\mu^{i} \in \Delta$, is not empty, then program (29) has solution, and vice versa. ${ }^{20}$ If program (29) has no solution, the only way the elite may have of credibly providing to the citizens the incentive to fight hard is to promise democracy, which according to Lemma 1 , is possible if and only if $\phi \geq \phi^{*}{ }^{21}$

The next lemma (Lemma 3) will demonstrate that whether program (29) has solution or not also depends on $\phi$. To state Lemma 3 , we need first to introduce some preliminary definitions.

Let $\tilde{\tau}^{p}(\eta)$ and $\bar{\tau}^{p}(\phi)$ be defined respectively as the minimum tax rate such that the incentive-compatibility constraint of the citizens-soldiers (12) holds in state $\mu^{p}$, and the maximum tax rate that the elite can credibly promise to the citizens in state $\mu^{p}$, when taxes are set in state $\mu^{u}$ and $\mu^{w}$ at level $\tau^{w}=\tau^{u}=\hat{\tau} .{ }^{22}$ The notation used emphasize that these taxes depend respectively on the cost of effort $\eta$ and of the cost of a military defeat $\phi$. Moreover, the tax rate $\tilde{\tau}^{p}(\eta)$ does not depend on the parameter $\phi$, capturing the permanent income loss caused by a military defeat. This is again because of the competitive assumption, which implies the effort decision of a single individual, has a negligible impact on $P_{t}$ and therefore is not affected by $\phi$. Similarly, the tax rate $\bar{\tau}^{p}(\phi)$ does not depend on $\eta$, since this parameter does not have any influence of the utility of the elite given that they do not fight in wars.

Let define $\eta^{*}$ as threshold value of $\eta$ that solves the following equation

$$
\tilde{\tau}^{p}(\eta)=\bar{\tau}^{p}\left(\phi^{*}\right) .
$$

\footnotetext{
${ }^{20}$ Program (29) corresponds to the maximization of a continuous function over a compact set and therefore, by Weierstrass theorem, it has a solution provided that the constraint set is not empty. Moreover, it is easy to verify that the constraint set can be non-empty for some admissible parameters combinations. For example, as $\eta$ tends to zero, the incentive-compatible redistribution also tends to zero, which clearly implies that the constraint set of program (29) is not empty.

${ }^{21}$ This follows from the fact, in this case, the program of the elite consists in maximizing a linear function over a non-empty compact set.

${ }^{22}$ Equivalently, $\tilde{\tau}^{p}(\eta)$ can be defined as the value of the tax rate $\tau^{p}$ such that (12) holds as equality when when $\tau^{w}=\tau^{u}=\hat{\tau}$. Also, $\bar{\tau}^{p}(\phi)$ can be defined as the value of the tax rate $\tau^{p}$ such that, for every $\mu^{i} \in \Delta$, condition (28) holds as equality, when $\tau^{w}=\tau^{u}=\hat{\tau}$.
} 
In words, $\eta^{*}$ is the value of $\eta$ such that the maximum intertemporal taxation that the elite can credibly commit to implement in state $\mu^{p}$ when $\phi=\phi^{*},{ }^{23}$ and expressed by the vector $\left[\hat{\tau}, \hat{\tau}, \bar{\tau}^{p}\left(\phi^{*}\right)\right]$, is just sufficient to satisfy the incentive-compatibility constraint (6) of the citizens. It can be shown that equation (30) has only one solution $\eta^{*}$, and that $\tilde{\tau}^{p}(\eta) \lessgtr \bar{\tau}^{p}\left(\phi^{*}\right)$ for any $\eta \lessgtr \eta^{*}$ and vice versa.

Lemma $3 \exists \phi=\phi^{* *} \in(0,1]$ such that program (29) has a solution if and only if $\phi \geq \phi^{* *}$. Moreover, $\phi^{* *}>\phi^{*}$ if and only if $\eta>\eta^{*}$.

\section{Proof. See Appendix.}

Lemma 3 provides a result similar to Lemma 2, since it tells us that strategy $\mathcal{R}$ is feasible only if the cost of a deviation for the elite, expressed by $\phi$, is sufficiently large (i.e. above the threshold $\left.\phi^{* *}\right)$. Moreover, according to Lemma 3, whether the threshold $\phi^{* *}$ is larger or smaller than $\phi^{*}$ depends on the individual effort cost $\eta$. In particular, if $\eta<\eta^{*}$, then $\phi^{* *}<\phi^{*}$, which implies that whenever democracy can be credibly promised by the elite, then an intertemporal incentive-compatible redistribution can also be promised by the elite to the citizens. This means that the concession of democracy does not increase the ability of the elite to commit to future redistribution. The opposite is true if $\eta>\eta^{*}$, which implies that $\phi^{* *}>\phi^{*}$. In this case, when $\phi \in\left(\phi^{*}, \phi^{* *}\right)$ the elite can make the credible promise to concede democracy after a war, but cannot credibly promise an incentive-compatible redistribution. Hence, when $\phi \in\left(\phi^{*}, \phi^{* *}\right)$ the concession of democracy is not only convenient to the elite, but it is also the only strategy that allows them to avoid losing wars.

\subsection{Characterization of the Subgame Perfect Equilibrium}

We can now describe the SPE of the political game that is best for the elite. However, we first remind that $\eta^{*}, \phi^{*}$ and $\phi^{* *}$ are defined respectively as in (30), (24) and Lemma 3. In strategy $\mathcal{R}$, the tax rates $\tau^{i}$, for all $i \in\{w, u, p\}$, are defined as the tax rates that are the solution to program (29). Moreover, let $\tilde{h}^{t-1}$ and $\hat{h}^{t-1}$ denote respectively the equilibrium aggregate histories induced by strategy $\mathcal{R}$ and $\mathcal{D}$, and let $\breve{h}^{t-1}$ denote the aggregate history induced by the fiscal policy implemented by democracy in the subgames beginning in state $D$. The following proposition offers a complete characterization of the SPE. ${ }^{24}$

\footnotetext{
${ }^{23}$ We remind that $\phi^{*}$ is defined in Lemma 1.

${ }^{24}$ Proposition 2 does not specify the government's strategy after any history where some deviation by the citizens has occurred. As explained before, this is because of the assumption that citizens make their war effort decision competitively and because of the assumption that state $C$ is absorbing.
} 
Proposition 2 The SPE of the dynamic political game that is best for the elite has the following form.

1. If $s_{t}=N$ and $\eta<\eta^{*}$, then

1a. If $\phi<\phi^{* *}$, the oligarchy chooses the strategy $\mathcal{N} \mathcal{A}$, setting $\tau^{N}\left(\mu_{t}, h^{t-1}\right)=0$, $\rho\left(\mu_{t}, h^{t-1}\right)=0$ and $\psi\left(\mu_{t}, h^{t-1}\right)=0$ for any $\mu_{t} \in \Delta$, and for any $h^{t-1} \in H^{t-1}$. Moreover, citizen $j$ chooses $e_{j, t}\left(\mu_{t}, h^{t-1}, z^{j, t-i}\right)=0$ if $\mu_{t}=\mu^{w}$, for any $h^{t-1} \in H^{t-1}$ and any $z^{j, t-i} \in\{0,1\}$. Thus, $s_{T}=s^{\infty}=C$.

1b. If $\phi \geq \phi^{* *}$, the oligarchy chooses strategy $\mathcal{R}$, setting $\tau^{N}\left(\mu_{t}, h^{t-1}\right)=\tau^{i}, \rho\left(\mu_{t}, h^{t-1}\right)=$ 0 and $\psi\left(\mu_{t}, h^{t-1}\right)=0$ if $\mu_{t}=\mu^{i} \in \Delta$ and $h^{t-1}=\tilde{h}^{t-1}$; and $\tau^{N}\left(\mu_{t}, h^{t-1}\right)=0$, $\rho\left(\mu_{t}, h^{t-1}\right)=0$ and $\psi\left(\mu_{t}, h^{t-1}\right)=0$ if $\mu_{t}=\mu^{i} \in \Delta$ and $h^{t-1} \neq \tilde{h}^{t-1}$. Moreover, citizen $j$ chooses $e_{j, t}\left(\mu_{t}, h^{t-1}, z^{j, t-i}\right)=1$ if $\mu_{t}=\mu^{w}, h^{t-1}=\tilde{h}^{t-1}$ and $z^{j, t-i}=0$; and $e_{j, t}\left(\mu_{t}, h^{t-1}, z^{j, t-i}\right)=0$ if $\mu_{t}=\mu^{w}$, and $h^{t-1} \neq \tilde{h}^{t-1}$ or $z^{j, t-i}=1$. This implies that the long run political regime is $s^{\infty}=N$.

2. If $s_{t}=N$ and $\eta \geq \eta^{*}$, then

2a. If $\phi<\phi^{*}$, the oligarchy chooses the strategy $\mathcal{N} \mathcal{A}$ and the equilibrium is the same as in case $1 a$.

2b. If $\phi^{*} \leq \phi<\phi^{* *}$, the oligarchy chooses strategy $\mathcal{D}$, setting $\tau^{N}\left(\mu_{t}, h^{t-1}\right)=0$, $\rho\left(\mu^{w}, h^{t-1}\right)=1$ and $\psi\left(\mu^{u}, h^{t-1}\right)=1$ for any $\mu_{t} \in \Delta$ and $h^{t-1}=\hat{h}^{t-1}$; and $\tau^{N}\left(\mu_{t}, h^{t-1}\right)=0, \rho\left(\mu_{t}, h^{t-1}\right)=0$ and $\psi\left(\mu_{t}, h^{t-1}\right)=0$ if $\mu_{t}=\mu^{i} \in \Delta$ and $h^{t-1} \neq \hat{h}^{t-1}$. Moreover, citizen $j$ chooses $e_{j, t}\left(\mu_{t}, h^{t-1}, z^{j, t-i}\right)=1$ if $\mu_{t}=\mu^{w}$ and $h^{t-1}=\hat{h}^{t-1}$; and $e_{j, t}\left(\mu_{t}, h^{t-1}, z^{j, t-i}\right)=0$ if $\mu_{t}=\mu^{w}$, and $h^{t-1} \neq \hat{h}^{t-1}$ or $z^{j, t-i}=1$. This implies that $s_{T+1}=D$, i.e. a transition to state $D$ occurs at time $T+1$.

2c. If $\phi \geq \phi^{* *}$, the oligarchy chooses the strategy $\mathcal{R}$ and the equilibrium is the same as in case $1 b$.

3. If $s_{t}=D$, then democracy sets $\tau^{D}\left(\mu_{t}, h^{t-1}\right)=\hat{\tau}$, for any $\mu_{t} \in \Delta$ and $h^{t-1}=\breve{h}^{t-1}$; and $e_{j, t}\left(\mu_{t}, h^{t-1}, z^{j, t-i}\right)=1$ if $\mu_{t}=\mu^{w}$ and $h^{t-1}=\breve{h}^{t-1}$, while $e_{j, t}\left(\mu_{t}, h^{t-1}, z^{j, t-i}\right)=0$ if $\mu_{t}=\mu^{w}$ and $h^{t-1} \neq \breve{h}^{t-1}$ or $z^{j, t}=1$. This implies that $s^{\infty}=D$, i.e. democracy is endogenously absorbing.

Proof. See Appendix. 
Proposition 2 clarifies the form of the SPE of the game, and how it depends on some key parameters of the model: the individual effort cost, $\eta$, and the aggregate loss caused by a military defeat, $\phi$. When the military effort cost of the citizens is small enough, i.e. when $\eta$ is below some threshold value $\eta^{*}$ (Case 1a and 1b), the elite choose either no action if $\phi$ is small enough (Case 1a) or, vice versa, to promise a credible incentive-compatible redistribution to the citizens (Case 1b). ${ }^{25}$ The first result (Case 1a) comes from the fact that when the disruption generated by a war loss is relatively small ( $\phi$ is below some threshold), the threat posed by war to the elite is smaller then the cost of preventing a military defeat. Hence, the elite find optimal choosing no action. When instead $\eta$ is sufficiently small (Case 1b), a deviation from strategy $\mathcal{R}$ is relatively unprofitable for the elite (recall that the incentive-compatible taxation is decreasing in $\eta$ ). This implies that the elite can credibly commit to an incentive-compatible redistribution whenever it can credibly commit to concede democracy (i.e. $\phi^{* *}<\phi^{*}$ ). Because the elite can commit to $\mathcal{R}$ for a larger set of parameters than they can commit to $\mathcal{D}$, and because $\mathcal{R}$ gives the elite a higher value than $\mathcal{D}$ (since democracy always taxes at maximum possible rate $\hat{\tau}$, i.e. the preferred tax of the citizens), democracy is never conceded in equilibrium, and the political state remains always equal to $N$.

When instead $\eta$ is relatively large (i.e., $\eta \geq \eta^{*}$ ), then democracy may be conceded by the elite in equilibrium when $\phi$ assumes intermediate values (Case 2b). This is because the incentive-compatible redistribution that needs to be promised to the citizens to induce them to put effort, is now sufficiently high that $\phi^{* *}>\phi^{*}$, i.e. strategy $\mathcal{R}$ is feasible for a smaller set of parameters than $\mathcal{D}$ is. In particular, when $\phi$ is in between $\phi^{*}$ and $\phi^{* *}$, the strategy $\mathcal{R}$ is not feasible for the elite, which prefer, by Lemma 1, to make the credible promise to concede democracy at the end of the war rather than facing a transition to state $C$. Finally, as before, when the war threat is very small (Case 2a) the optimal strategy of the elite is to choose strategy $\mathcal{N} \mathcal{A}$, and when it is very high (Case 2c), the strategy $\mathcal{R}$ which is both optimal and feasible for the elite.

It must be emphasized that the presence of a variable degree of external threat in periods of peace, is crucial to explain the difference between the mere provision of some income redistribution in the favor of the citizens, and the concession of democracy. If all periods of peace were alike, i.e. the probability of transition to a state a war was always the same, then democracy would not serve the purpose of providing an additional commitment device to the elite. This is because if the promise of the elite to concede democracy after a war is credible, so is the promise to implement at anytime in the future the same redistribution that democracy

\footnotetext{
${ }^{25}$ We remind for convenience that the threshold $\eta^{*}$ is independent of $\phi$.
} 
implements (i.e. the maximum feasible redistribution). If instead not all periods of peace are alike as we assume, and some are "more peaceful" then others, than conceding democracy in the period of unstable peace following a war, allows the elite to commit to redistributing income also in the future periods of stable peace, when the incentive for the elite to break a promise of redistribution is stronger.

\section{Some Historical Evidence}

In the modern era, mass-armies first appeared in France in 1793, when the National Convention decreed the famous levée en masse, in response to the continuous worsening of the military situation in the war begun the previous year against an anti-revolutionary coalition formed by several European powers. ${ }^{26}$ The new military model adopted by France proved to be so successful that mass-armies were quickly adopted by a number of other European countries during the Napoleonic Wars. The adoption of mass-armies had indeed significant consequences, including of stimulating a number of important reforms (discussed in detail below) in those European countries, such as Prussia/Germany, which had made a permanent transition to the new form of military organization. Interestingly, the Prussian autocracy was able to form a highly effective mass-army by making primarily social and economic concessions to the citizens, but only marginal political reforms.

However, after the end of the Napoleonic wars, several other European countries (including France itself $)^{27}$ decided to rely once again on a professional army, of relatively small size and formed by volunteers or mercenaries rather than by conscripts. As a result, the military innovations first introduced by revolutionary France had, overall, only limited political consequences in Europe through the $19^{\text {th }}$ century. ${ }^{28}$

Indeed, at the beginning of the $20^{\text {th }}$ century, the process of democratization of Europe was in many respects very far from being completed. For instance, the fraction of the population enfranchised in most European countries before World War I was generally smaller than one

\footnotetext{
${ }^{26}$ Interestingly, the proclamation of the levée en masse came along with that of a new constitution, the socalled Montagnard Constitution, prescribing universal suffrage as opposed to the limited franchise contemplated by the previous constitution of 1791 . This new constitution never became effective however.

${ }^{27}$ France adopted once again universal conscription only in 1875, in consequence of the defeat suffered during the Franco-Prussian War, which clearly revealed the superiority of mass-armies over professional militaries. The return to the model of mass-army took place in concomitance with a transition to democracy occurred with the proclamation of the constitution of the Third Republic in 1875.

${ }^{28}$ The reversion to professional militaries after the Napoleonic Wars was of course related to the relatively peaceful international climate promoted by the creation of the "Concert of Europe" at the Congress of Vienna, which persisted with few limited interruptions (e.g. the War of Crimea and the Franco-Prussian War) until of the outbreak of World War I.
} 
fourth, and did not include women. ${ }^{29}$ Moreover, the political voice of the lower classes was subject to substantial restrictions of various nature, even where the right to vote was formally conceded to a relatively large part of the society. In this respect, Halperin (2004 p. 131) writes that "Where the suffrage included members of the poorer classes, three-class and other weighted and plural voting systems, as well as open balloting and restrictions on and biases against working-class organizations and parties, made it futile for poor people to vote." 30 Other electoral techniques used to limit the power of the masses were the practice of declaring arbitrarily void an election whose results went against the incumbent government, and the requirement to pay a minimum direct tax in order to vote. ${ }^{31}$ As a result, according to Halperin, "In nearly all states in Europe, the franchise remained highly restricted until after World War II. On the eve of World War I, Norway was the only country in Europe with universal and equal suffrage. It was only after World War II that universal, equal, direct, and secret suffrage became the norm throughout Western Europe."

The waging of two total wars in the $20^{\text {th }}$ century required indeed the mobilization of both soldiers and civilians to an extent hardly ever observed before in the course of history. For instance, between 1914 and 1918 the U.K. mobilized as many as 6.2 million men, corresponding to $13 \%$ of its total population, while Germany and France drafted roughly $20 \%$ of their population, namely 13.25 and 8.2 million men respectively. The corresponding figures relative to World War II are even more impressive. Several authors have suggested, consistently with our theory, that the mass warfare peculiar of the first part of $20^{t h}$ century, has been a driving force of the process of transition of the Western world toward the adoption of universal franchise and the establishment of stable democracy. For example, Mann (1988 p. 158) writes in this respect that "But also, the experience of the middle class before the war-progress through the nation - now became more generalized to the people as a whole. The people sacrificed but not for nothing. A bargain was struck, fairly explicitly, at the end of the war there would be extension of the franchise (probably including women) and welfare reforms." Along the same lines, Porter (1994 p. 150) writes that, "As the only full-scale wars ever fought among industrialized powers, the First and Second World Wars produced permanent changes in the

\footnotetext{
${ }^{29}$ For example, the percentage of the population enfranchised in 1910 was 22 in Germany, Belgium, Switzerland, 21 in Austria, 19 in Sweden, 18 in the U.K., 17 in Denmark, 14 in the Netherlands and 8 in Italy. In a few countries the enfranchised share of the population war larger by the same year (45 percent in Finland, 33 in Norway and 29 in France).

${ }^{30}$ Open balloting consists in voting "openly," i.e. declaring the vote in public. This procedure allowed the local elite to easily threaten of punishment whoever voted "badly." Weighted voting systems attached more importance to the vote of the wealthy and/or educated people.

${ }^{31}$ Goldstein (1951 ch. 1) presents an extensive discussion of how voting procedures and electoral laws substantially violated the one-man-one-vote principle in $19^{\text {th }}$ century Europe.
} 
internal organization and structure of virtually all European states." The same author adds that the modern state born from the two World Wars had a structure articulated in a mass state, in which the political voice of the people was finally separated from their socioeconomic status as well as a welfare state, taking care of the well-being of its citizens. And everywhere in Europe the working class movement requested political participation in exchange of war participation. As explained by Andreski (1968 p. 27), "The passive resistance of the masses is most dangerous to the ruling group when the state is fighting for survival. At such times, if the willing cooperation of the masses is militarily essential, an effort must be made to win them over, to convince them that they are fighting for themselves." Finally, Hobsbawm (1990) remarks that it was widely accepted by the national elite that the First World War could not have been won without the support of the masses and that all governments tried to present the conflict primarily as a threat to the interests of the latter as well as the occasion for a social transformation of the country in their favor. ${ }^{32}$

In the following subsections, we discuss at greater length the causal nexus between warfare and the extension of political and social rights identified by our theory in Germany, England and the United States. These countries were chosen since they provide a clear illustration of the two possible diverging patterns of political development contemplated by our model: one involving the concessions of social reforms only, and the other involving the transition to consolidated democracy. We then also briefly discuss the examples of some non-Western countries (essentially those in Latin America and Africa), which experienced neither the creation of a welfare state, nor a transition to democracy, in relation to their virtual insulation from mass warfare over the last century.

\subsection{The Case of Prussia/Germany}

A sequence of major social and institutional reforms was undertaken by the Prussian government in the aftermath of the military defeat inflicted by Napoleon to the Prussian army at the battle of Jena (1806), which was arguably instrumental in creating both the awareness of the need, and a wide political support for a substantial transformation of the status quo. One of the first major socioeconomic reforms undertaken by the Prussian leaders was the abolition of serfdom (1807), aimed at the creation of a class of small land owners. Another important administrative reform involved the creation of a representative organ at the municipal level, based on a relatively large suffrage. At the same time, a number of military reforms radically

\footnotetext{
${ }^{32}$ Dolman (2004 p. 27) presents quantitative evidence relative to Western countries over the period 18601992, suggesting that a sizable extension of franchise follows each significant rise of incorporation of civilians into military service.
} 
transformed the Prussian army into an organization based on conscription similar to the Grand Armée. The law of September 3, 1814, required all Prussians subjects to serve five years in the standing army (three on active service and two in the reserve) and fourteen years in the militia, or Landwehr.

Andreski (1968 p. 69) explicitly links with the advent of mass-armies and the age of the reform in Prussia, writing that "The advent of mass-armies produced a new situation. The loyalty of the lower classes had to be strenghtened by extending to them various rights. In Prussia, and later in Germany, this policy was perhaps most deliberate. Serfdom was abolished concurrently with the military reforms of Stein, and peasants were granted the free ownership of the land they cultivated." Skocpol (1979 p. 108) also emphasizes the military rationale behind the abolition of serfdom, as she writes that "Serfs were given their personal freedom. And universal military conscription was begun, a measure that allowed the Prussian armies to expand suddenly and to benefit from the increased enthusiasm of citizens newly benefited by the reforms or aroused to hostility by several years of French intervention and financial exactions." 33

A major reason for the eagerness of the Prussian government to undertake many radical reforms (and for the relative lack of opposition to them by the Junkers) was the exceptional external military challenge that Prussia (and later Germany) constantly faced due to the geographic position (located at the center of Europe and between the East and the West) and configuration (shaped by the lack of natural boundaries protecting the national territory from invasion by foreign armies). This point is clearly emphasized by Huntington (1957 p. 33) who writes that: "Lacking natural boundaries, and with her territories scattered all over Germany, Prussia was uniquely dependent upon strong military force to maintain her independence and integrity. The rulers of Prussia had been aware of this since the middle of the seventeenth century and had poured tremendous resources and manpower into the maintenance of an efficient standing army throughout the eighteenth century."

According to our model, it is precisely the exceptionally serious external threat - corresponding in our model to a value of $\phi$ above the critical threshold $\phi^{* *}$ - faced by Prussia and later by Germany, that explains why its government could mobilize the masses by granting them social reforms only, rather than by conceding democracy. Indeed, significant social

\footnotetext{
${ }^{33}$ Interestingly, the major defeat suffered in the Crimean War (1853-56), triggered a somewhat similar path of social and military reforms also in Russia. In particular, in 1861 Alexander II issued his Emancipation Manifesto that proposed 17 legislative acts that would free tens of millions of serfs. The czar announced that personal serfdom would be abolished and all peasants would be able to buy land from their landlords. At the same time, the military was transformed from a professional force into an army recruited with mass conscription.
} 
reforms continued to be granted later on under the leadership of Bismarck. For instance, compulsory sickness insurance was introduced in 1883, an accident insurance in 1884 and 1885 and a pension system providing assistance to the aged and to the disabled in 1889. As a result, by the end of the $19^{\text {th }}$ century, Germany had established the most comprehensive system of social insurance and of work protection in the world.

Yet, despite having an impressively advanced social legislation, the Second Reich never evolved in a true constitutional monarchy based on the principle of popular sovereignty and democratic representation. Universal suffrage had indeed been formally introduced in Germany as early as in 1871 (the year of birth of the new nation). However, the real political power belonged to the Bundesrat, which was controlled by Prussia; in turn Prussia was ruled, through a three-tiered voting system, by its economic elite, which included both industrialists and the Junkers. As a result, Germany remained de facto an autocracy until the end of World War I.

A major impulse toward the creation of an effective democracy in Germany, was indeed provided by the endurance of the First World War. Chancellor von Bethman-Hollweg warned at some point the Prussian war cabinet that the continuation of war required an electoral reform. In January of 1916 and later in his Easter Degree of 1917, the Kaiser indeed promised the concession of a truly equal suffrage at the end of the war, through the abolition of the three-tiered electoral system, and a reform of the upper chamber of the Parliament, (Porter 1994 p. 173, Dolman 2004 p. 148). ${ }^{34}$ Moreover, a special committee was immediately created to examine the question of a post-war constitutional reform.

Democracy was finally introduced in Germany in 1919, following its defeat in the Great War. It is undeniable that a serious revolution threat existed in Germany at that time, greatly fuelled by the crushing military defeat suffered by the country, and that this threat is likely to have played an important role in the creation of a parliamentary democracy (e.g. Therborn, 1977). Nonetheless, the evidence discussed above suggests that, had Germany won the war, the introduction of democracy, as the fulfillment of the wartime promises made by the Kaiser, may perhaps have been as well on agenda.

\subsection{The Cases of Britain and of the U.S.}

Unlike Germany, Great Britain and the U.S. represent examples of countries where the involvement in mass warfare has lead to a progressive extension of franchise (albeit at a somewhat different pace), culminated in universal suffrage.

\footnotetext{
34 "In order to maintain the war spirit of the nation, the Kaiser's military government issued public promises that if the army could prevail, future military and political reforms would be forthcoming, but the crisis was not the time for change." (Dolman 2004 p. 148).
} 
Britain was at the lead of the process of democratization of the West during the $19^{\text {th }}$ century, as franchise was extended there for three times (1832, 1867 and 1884). During this period, no major war comparable to the Napoleonic Wars was fought in Europe, and the factors that have played a key role in the progressive democratization of England can be found in the threat of the explosion of a social revolution (Acemoglu and Robinson, 2000) and in the existence of an intra-elite conflict (Lizzeri and Persico 2004, Llavador and Oxoby, 2005). Nevertheless, as explained before, at the end of the $19^{t h}$ century the democratization of Britain was far from being complete. The total wars of the $20^{\text {th }}$ century, which Britain fought with conscript armies (with the exception of the first part of World War I), transformed dramatically the British society and its government. Near the end of the First World War, the British Parliament passed the Representation of the People Act, extending franchise to all adult males and many females. The number of qualified voters raised from 8 to 21 million, corresponding to three quarters of the adult population: for the first time in history, the House of Commons would have been elected by a majority of British citizens. Moreover, the system of plural voting lost much importance after 1918, and it was formally abolished in 1948, three years after the end of the Second World War (see Therborn 1977 p. 8).

Our model suggests that the smooth transition of Britain to full democracy may have originated from the fact that its involvement in the two world wars, was somehow limited due to geographic factors. In particular, the insular nature of Britain arguably made a potential military defeat appear less costly (i.e. let the parameter $\phi$ be in the intermediate region defined by two thresholds $\phi^{*}$ and $\phi^{* *}$ ), and therefore required the concessions of democracy as opposed to redistribution only. This is consistent with the explanation for the introduction of universal suffrage in Britain provided by Giddens (1987 p. 234), who writes that "As soon as the unification of Germany occurred Bismarck established universal male suffrage, as a response to what he saw as the military exigencies of the new state. In countries lacking a proximate revolutionary background and not so directly involved in European war, most notably Britain, the extension of franchise tended to be halting. Only with the experience of the First World War, in which conscription was not introduced until the armed forces had suffered huge losses, was universal male suffrage instituted. Once more, this was done in explicit recognition of the ties between citizenship rights and military obligations."

Many historians have also emphasized the causal link existing between the involvement of the U.S. in major wars, and their progressive transition to democracy. For example, in his account of the history of franchise in the U.S., Keyssar (2000) argues that the process of expansion and retrenchment of the right to vote in America reflects the dynamic conflict between class 
tensions, pushing to its restriction, and the exigencies of war, fostering its diffusion. Keyssar (p. xxi) writes that "...Nearly all of the major expansions of the franchise that have occurred in American history took place either during or in the wake of wars. The historical record indicates that this was not a coincidence: the demand of both war itself and preparedness for war created powerful pressures to enlarge the right to vote. Armies had to be recruited, often from so-called lower orders of society, an it was rhetorically as well as practically difficult to compel men to bear arms while denying them the franchise." 35

Some of the most important steps of the process of democratization of the U.S. that highlight the connection between participation to the war effort and the extension of political right suggested by our theory, include the introduction of universal male suffrage, essentially to the benefit of ethnic minorities such as African Americans (1869), the extension of the right to vote to women (1920) and the decision of the Supreme Court to declare the white primary unconstitutional (1944).

The Fifteenth Amendment extended the voting right to African American males in 1869. The Republicans, who controlled most state legislatures, argued that black men had earned the right to vote because of the heroism they demonstrated as soldiers in the Civil War. Indeed, African American supported with loyalty the cause of the Union, fought with dedication and died to preserve it. ${ }^{36}$ Suffrage was extended to women by the Nineteenth Amendment in 1920. The amendment was also actively supported "as a war measure" by President Wilson in an extraordinary address in January 1918. In another address to the Senate in September 1918, Wilson returned again on the link between franchise and the war effort of women, arguing that this was essential for the prosecution of the conflict. ${ }^{37}$ The Suffragists themselves stressed the importance of wartime role of women, and even threaten to diminish their effort if suffrage were not forthcoming. In 1944, the Supreme Count declared in Smith v. Allwright, that the white primary, one of the most effective methods to actually deny the vote to African American,

\footnotetext{
${ }^{35}$ Keyssar (p. 36) also identifies the reason behind the willingness of the middle-upper classes to extend franchise as he writes: "Why did voting members of the community sometimes elect to share their political power with others? In numerous cases, it was because they saw themselves as having a direct interest in enlarging the electorate. One such interest was military preparedness and the defense of the republic. In the wake of the Revolutionary War and again after the War of 1812, many middle-class citizens concluded that extending the franchise to the "lower orders" would enhance their own security and help to preserve their way of life, by assuring that such men would continue to serve in the army and the militia."

${ }^{36}$ The importance of the war effort of the African American, as well as its political significance, were explicitly recognized also by military leaders. For instance, General William Sherman (quoted in Keyssar 2000 p. 88) declared that: "when the fight is over, the hand that drops the musket cannot be denied the ballot."

${ }^{37}$ Wilson (quoted in Keyssar 2000 p. 216) declared that women's suffrage was "essential to the successful prosecution of the great war of humanity in which are engaged... We have made partners of the women in this war. Shall we admit them only to a partnership of sacrifice and suffering and toll and not to a partnership of privilege and of right? This war could not have been fought... if it had not been for the services of women."
} 
was unconstitutional. While this was a judicial, rather than a political, decision, the judges themselves were arguably not at all indifferent to the exigencies of war. Indeed, an important commentator of the New York Times, the Supreme Court reporter Arthur Krock, argued that the Court's decision in the Smith v. Allwright case was strongly related to exceptional circumstances of the war. ${ }^{38}$

Similarly to Britain, geographic factors (and the related limited expected cost of a military defeat) arguably explain why the involvement of the U.S. in mass warfare, did lead to the concessions of democracy rather than of income redistribution alone.

\subsection{No War, No Democracy? Africa and Latin America}

The cases of Africa and Latin America provide additional interesting evidence on the relation between warfare and political and social change. It is been widely argued (e.g. Herbst, 2000, Centeno 2002) that the relative insulation from major wars during the $20^{\text {th }}$ century has been a crucial determinant of the distinctive path of political and institutional evolution experienced by many African and Latin American countries. ${ }^{39}$

In particular, Centeno (2002) argues that the Latin American states system has always been remarkably peaceful during all of the $20^{\text {th }}$ century, due to the lack of incentives for nations to wage war against each other. In turn, the remarkable rarity of major international conflicts, partly explains the slow transition to democracy of Latin American states, whose elite were not compelled to make political concessions by the need of mobilizing the masses in order to sustain the war effort. ${ }^{40}$ Therborn (1977) also suggests the existence of a similar causal relation between the insulation of Latin American states from the two world wars, and the fragility of their democratic institutions.

Perhaps even more importantly, the nature of the wars fought in Europe during the $20^{\text {th }}$ century has been strikingly different from the nature of the wars occasionally fought in Africa and Latin America over the same period of time. European wars have been total wars while

\footnotetext{
${ }^{38}$ Krock (quoted in Keyssar 2000 p. 248) wrote that the "real reason for the... [decision was] that the common sacrifices of wartime have turned public opinion and the court against previously sustained devices to exclude minorities from any privilege of citizenship."

${ }^{39}$ Latin America experienced a significant period of international military rivalry and warfare in the aftermath of the Decolonization process, occurred in the first decades of the $19^{\text {th }}$ century. However, this military rivalry was short-lived and virtually vanished by the beginning of the $20^{\text {th }}$ century. Vice versa, Africa did not essentially experienced Decolonization until the post-World War II period, and was relatively peaceful thereafter. See Herbst (2000) and Centeno (2002) for more on this point.

${ }^{40}$ Centeno (2002 pp. 30-31) claims that: "The Latin American states were never strong enough to demand full conscription. Perhaps more important, there was never a perceived need for the kind of social upheaval implied by mass armies. The state did not need the population, as soldiers or even as future workers, and thus could afford to exclude it."
} 
African and Latin American wars have been limited conflicts, causing a substantially lower disruption of income and wealth (Centeno, 2002). The degree of disruptiveness of a conflict is captured in our model by the parameter $\phi$ : a total war is associated with a relatively high value of $\phi$, and a limited war with a relatively low value of $\phi$. Our model predicts that countries exposed to limited wars (i.e. which lead the disruption of a proportion of income lower than the threshold $\phi^{*}$ ) should be expected to experience neither democratic transitions, nor welfare state expansions. This prediction appears indeed consistent with the historical experience of both Africa and Latin America over the last century.

\section{Conclusions}

In this paper, we have offered a theory of political transitions which focuses on the interaction between international conflicts and the domestic conflict of interest over fiscal policy between upper and lower classes. We have argued that democracy and redistributive policies represent concessions that the elite may choose to make to the citizens in order to increase their willingness to put effort in fighting in mass-armies. The resulting higher martial effectiveness of the army can more than compensate the elite for the redistribution of income and for the loss of political power, by making a military defeat (and the consequent aggregate income loss) more unlikely to occur. Moreover, we have shown that democracy is conceded by the elite as a commitment device to future income redistribution when a mere promise of it is not credible.

Our theory offers a novel explanation for why many episodes of democratic transitions through the $19^{\text {th }}$ and especially the $20^{\text {th }}$ century have occurred in the aftermath of major wars. We can explain why democracy is relatively unlikely to emerge and to consolidate in presence of a very serious as well as limited or absent external threat. In fact, in the first case, the elite can make credible promises of income redistribution to induce the citizens to put high effort in fighting wars, while in the latter case the elite are not compelled to make any kind of concession at all.

Our theory is also broadly consistent with the empirical evidence recently provided by Reiter and Stam (2002) which demonstrate that democratic soldiers are significantly superior in terms of military effectiveness, as represented by leadership and initiative on the battlefield, after controlling for factors such as the level of economic development. Reiter and Stam interpret their findings as evidence that democratic soldiers are indeed more motivated to fight, and do so better, than soldiers serving in the armies of non-democratic states. ${ }^{41}$

\footnotetext{
${ }^{41}$ For instance, Reiter and Stam write (p. 61) that "States must ask citizens to make individual sacrifices, whether to pay taxes, to sacrifice their liberty by serving in the military, or to risk their lives on the battlefield.
} 
A number of important questions remain open for future research. For example, an interesting extension of our model would be to make endogenous the probability of war by analyzing the incentives of the states to engage in international wars. Also, it would be worth studying the impact of warfare on other types of political institutions. Finally, it would be interesting to provide a careful quantitative assessment of the impact of wars on democratization.

\section{Appendix}

\subsection{Proof of Lemma 3}

To determine if program (29) has a solution or not, we begin by determining what is the maximum amount of intertemporal redistribution that the elite can credibly commit to provide to the citizens when $s=N$. Clearly, this corresponds to the vector of taxes such that the three no-deviations conditions of the elite in the three possible states of the world, expressed by (28), all hold as equalities. This requirement leads to a system of three equations, that can be written in compact form as

$$
V^{H}\left(N, \mu^{i},\left[\tau^{w}, \tau^{u}, \tau^{p}\right]\right)=\tilde{V}^{H}\left(N, \mu^{i}\right)
$$

for any $\mu^{i} \in \Delta$. We remind that, for given $\left[\tau^{w}, \tau^{u}, \tau^{p}\right]$, the values $V^{H}\left(N, \mu^{i},\left[\tau^{w}, \tau^{u}, \tau^{p}\right]\right)$ are provided by the solution of the recursions (25), (26) and (27), and the values $\tilde{V}^{H}\left(N, \mu^{i}\right)$ are expressed by $(21),(22)$ and (23). It can be readily verified that the values $V^{H}\left(N, \mu^{i},\left[\tau^{w}, \tau^{u}, \tau^{p}\right]\right)$ are linear in $\tau^{w}, \tau^{u}$, and $\tau^{p}$ and therefore the system of equations expressed by (31) has at the most one solution (given that the three corresponding equations are linearly independent), which is expressed by the vector $\left[\bar{\tau}^{w}, \bar{\tau}^{u}, \bar{\tau}^{p}\right]$.

It is also straightforward to verify that $\bar{\tau}^{i}$ is an increasing function of $\phi$ for each $i \in\{w, u, p\}$, and such that $\bar{\tau}^{i}(\phi) \downarrow 0$ if $\phi \downarrow 0$. Using this fact, we can define more formally the set of tax vectors $\left[\tau^{w}, \tau^{u}, \tau^{p}\right]$ that the elite can credibly promise to the citizens as

$$
B(\phi) \equiv\left\{\left[\tau^{w}, \tau^{u}, \tau^{p}\right]: \tau^{w} \leq \bar{\tau}^{w}(\phi), \tau^{u} \leq \bar{\tau}^{u}(\phi), \tau^{p} \leq \bar{\tau}^{p}(\phi)\right\}
$$

where the notation used emphasizes that the set depends on the parameter $\phi$. For future reference, we observe here that the schedules $\bar{\tau}^{i}(\cdot)$ do not depend on $\eta$, and therefore the measure of set $B(\phi)$ also does not depend on $\eta$.

Soldiers are more likely to accept the dangers of the battlefield and place their lives at risk if they are serving in a military overseen by a government grounded in democratic political institutions. They are more likely to perceive the war effort and the leadership itself as reflecting their own interests if the need for popular consent constraints the government and can be removed from office if it fails to hold up its end of the social contract." 
The rest of the proof of is organized as follows. First, we characterize an important monotonicity property of the set $B(\phi)$ and of the solution of program (29) (Claims 1 and 2), which is used to prove the first part of the lemma. Then, we provide a necessary and sufficient condition for program (29) to have a solution at $\phi=\phi^{*}$ (Claims 3 and 4 ) in terms of a threshold value of $\eta$. Finally, we use all the results obtained to prove the second part of the lemma.

The set $B(\phi)$ has the following important property,

Claim 1 The set $B(\phi)$ defined in (32) is such that

$$
B\left(\phi_{1}\right) \subseteq B\left(\phi_{2}\right)
$$

for each $\phi_{1}$ and $\phi_{2}$ such that $\phi_{1} \leq \phi_{2}$.

Proof. It follows immediately from the increasing monotonicity of $\bar{\tau}^{i}$ with respect to $\phi$, for any $i \in\{w, u, p\}$.

We also remark for future reference, that $\bar{\tau}^{i}$, and therefore the set $B(\phi)$, does not depend on $\eta$, since neither side of (31) depends on the effort cost of the citizens.

Program (29) has a solution if the set $B(\phi)$ has a non-empty intersections with the set $E$ of the triples $\left[\tau^{w}, \tau^{u}, \tau^{p}\right] \in[0, \hat{\tau}]^{3}$ such that condition (12) holds, i.e. if $B(\phi) \cap E \neq \varnothing$.

Now, let $\phi^{* *}$ denote the infimum of the set of values of $\phi$ such that program (29) has a solution, or

$$
\phi^{* *} \equiv \inf \{\phi \in(0,1): B(\phi) \cap E \neq \varnothing\} .
$$

The following is an immediate consequence of Claim 1 and of a property of the set $E$.

Claim 2 Suppose that $\phi^{* *}$, as defined in (34), exists. Then, program (29) has a solution for some $\phi$ if and only if $\phi \geq \phi^{* *}$.

Proof. Because the frontier of the set $E$ does not depends on $\phi$ (since neither side of (12) depends on this parameter), the monotonicity property of $B(\phi)$ reported in Claim 1 implies that, if $\phi^{* *}$ exists, then $B(\phi) \cap E \neq \varnothing$ for any $\phi>\phi^{* *}$. Also, by definition of $\phi^{* *}$, we have that $B(\phi) \cap E=\varnothing$ for any $\phi<\phi^{* *}$.

If $\phi^{* *}$, as defined in (34) does not exist, then the same reasoning as in the proof of Claim 2 , implies that program (29) has no solution for any value of $\phi$, and we conventionally set $\phi^{* *}=1$. Note also that $\phi^{* *}>0$ since $B(0)=\varnothing$ (i.e. if wars cause no income loss the elite cannot credibly promise any positive level of taxation). This proves the first part of Lemma 3 . 
To prove the second part of Lemma 3 , let us consider in particular the set $B\left(\phi^{*}\right)$, where $\phi^{*}$ is defined implicitly by (24). We remind that, when $\phi=\phi^{*}$, the promise made by the elite in state $\mu^{w}$ to concede democracy in state $\mu^{u}$ is credible, i.e. in state $\mu^{u}$ the elite prefer to be taxed at the maximum possible level $\hat{\tau}$ in every state of the world (which according to Proposition 1 is the fiscal policy chosen by democracy) rather then deviating and obtaining the corresponding value $\tilde{V}^{H}\left(N, \mu^{u}\right)$ defined by $(21)$. It follows that, if $\phi=\phi^{*}$, the elite can credibly commit in state $\mu^{w}$ to set taxes in state $\mu^{u}$ at the level $\hat{\tau}$. Furthermore, because $\tilde{V}^{H}\left(N, \mu^{u}\right)>\tilde{V}^{H}\left(N, \mu^{w}\right)$ (see the proof of Lemma 1), in state $\mu^{w}$ the elite are also better-off in an equilibrium where taxes are always set at the constant level $\hat{\tau}$, then by deviating from such equilibrium, and experiencing a sudden military defeat. We then have that the solution of (31) is such that $\bar{\tau}^{u}\left(\phi^{*}\right)=\bar{\tau}^{w}\left(\phi^{*}\right)=\hat{\tau}$, and $\bar{\tau}^{p}\left(\phi^{*}\right)$ is determined as the solution of equation

$$
V^{H}\left(N, \mu^{p},\left[\tau^{w}, \tau^{u}, \tau^{p}\right]\right)=\tilde{V}^{H}\left(N, \mu^{p}\right),
$$

imposing that $\tau^{u}=\tau^{w}=\hat{\tau}$, and the set $B(\phi)$ has the following form

$$
B\left(\phi^{*}\right) \equiv\left\{\left[\tau^{w}, \tau^{u}, \tau^{p}\right]: \tau^{w} \leq \hat{\tau}, \tau^{u} \leq \hat{\tau}, \tau^{p} \leq \bar{\tau}^{p}\left(\phi^{*}\right)\right\}
$$

In particular, it can be demonstrated that $\bar{\tau}^{p}\left(\phi^{*}\right)<\hat{\tau}$. To prove this, recall that in the proof of Lemma 1 it has been demonstrated that for any $\phi, \tilde{V}^{H}\left(N, \mu^{p}\right)>\tilde{V}^{H}\left(N, \mu^{u}\right)$, and that, by definition of $\phi^{*}, \tilde{V}^{H}\left(N, \mu^{u} \mid \phi=\phi^{*}\right)=V^{H}(D)$. Combining these results, using the fact that $V^{H}(D)=V^{H}\left(N, \mu^{p},[\hat{\tau}, \hat{\tau}, \hat{\tau}]\right)$, and equation (35), we obtain that

$$
V^{H}\left(N, \mu^{p},\left[\hat{\tau}, \hat{\tau}, \bar{\tau}^{p}\left(\phi^{*}\right)\right]\right)>V^{H}\left(N, \mu^{p},[\hat{\tau}, \hat{\tau}, \hat{\tau}]\right) .
$$

which clearly implies that $\bar{\tau}^{p}\left(\phi^{*}\right)<\hat{\tau}$.

Program (29) has a solution at $\phi=\phi^{*}$ if the maximum amount of intertemporal redistribution that the elite can promise, i.e. corresponding to the taxes vector $\left[\hat{\tau}, \hat{\tau}, \bar{\tau}^{p}\left(\phi^{*}\right)\right]$, satisfies the incentive-compatibility constraint of the citizens-soldiers (12).

To determine if this is the case or not, define $\tilde{\tau}^{p}$ as the level of $\tau^{p}$ such that (12) holds as equality with $s_{t}=N$ for all $t$, and $T_{t}=\tau_{t} Y$, and $\tau^{w}=\tau^{u}=\hat{\tau}$. The corresponding vector of taxes $\left[\hat{\tau}, \hat{\tau}, \tilde{\tau}^{p}\right]$ is incentive-compatible for the citizens by construction, and can be directly compared with the vector $\left[\hat{\tau}, \hat{\tau}, \bar{\tau}^{p}\left(\phi^{*}\right)\right]$ defined above.

In particular, by the analysis made above, if $\bar{\tau}^{p}\left(\phi^{*}\right) \geq \tilde{\tau}^{p}$, or equivalently if $\left[\hat{\tau}, \hat{\tau}, \tilde{\tau}^{p}\right] \in$ $B\left(\phi^{*}\right)$, then program (29) has a solution when $\phi=\phi^{*}$. Moreover if $\bar{\tau}^{p}\left(\phi^{*}\right)<\tilde{\tau}^{p}$, or equivalently if $\left[\hat{\tau}, \hat{\tau}, \tilde{\tau}^{p}\right] \notin B\left(\phi^{*}\right)$, then the maximum amount of redistribution the elite can credibly promise to the citizens is not sufficient to induce them to put effort in war periods. This leads to the following Claim. 
Claim 3 When $\phi=\phi^{*}$, program (29) has a solution if and only if $\left[\hat{\tau}, \hat{\tau}, \tilde{\tau}^{p}\right] \in B\left(\phi^{*}\right)$.

It can be demonstrated that $\left[\hat{\tau}, \hat{\tau}, \tilde{\tau}^{p}\right] \in B\left(\phi^{*}\right)$ if the value of the individual effort cost parameter $\eta$ is sufficiently small.

Claim $4\left[\hat{\tau}, \hat{\tau}, \tilde{\tau}^{p}\right] \in B\left(\phi^{*}\right)$ if and only if $\eta \leq \eta^{*}$, where $\eta^{*}$ is the unique solution of equation (30).

Proof. Denote $\tilde{\tau}^{p}=\tilde{\tau}^{p}(\eta)$ as the function obtained by letting the tax rate $\tilde{\tau}^{p}$ defined above vary with $\eta$. Solving the system of recursions (7), (8) and (9) by assuming that $\tau^{w}=\tau^{u}=\hat{\tau}$, and that the incentive-compatibility constraint (12) holds as equality when the political state is permanently $s=N$, i.e. that

$$
\alpha \beta\left[V^{L}\left(N, \mu^{u}\right)-\hat{V}^{L}\left(N, \mu^{u}\right)\right]=\eta,
$$

it can be verified that

$$
\tilde{\tau}^{p}(\eta)=c_{0}+c_{1} \eta
$$

where $c_{0}$ and $c_{1}$ are constants depending on a list of parameters of the model, but not on $\phi$, with $c_{0}<0$ and $c_{1}>0$.

Because $\tilde{\tau}^{p}(\cdot)$ is a continuous and strictly increasing function of $\eta$ (since the constant $c_{1}$ defined above is strictly positive), and such that $\tilde{\tau}^{p}(\eta) \downarrow c_{0}<0$ as $\eta \downarrow 0$ and $\tilde{\tau}^{p}(\eta) \uparrow \infty$ as $\eta \uparrow \infty, \exists ! \eta \in \mathbb{R}_{+}$such that $\tilde{\tau}^{p}(\eta)=\tau$ for any $\tau \geq 0$. Also, because, as remarked previously, both the schedule $\bar{\tau}^{p}(\cdot)$ and the threshold $\phi^{*}$ do not depend on $\eta$, the properties of the schedule $\tilde{\tau}^{p}(\cdot)$ imply that $\exists \eta=\eta^{*}$ such that $\tilde{\tau}^{p}(\eta) \leq \bar{\tau}^{p}\left(\phi^{*}\right)$ for any $\eta \leq \eta^{*}$ and $\tilde{\tau}^{p}(\eta)>\bar{\tau}^{p}\left(\phi^{*}\right)$ for any $\eta>\eta^{*} .^{42}$ It immediately follows from these results that $\left[\hat{\tau}, \hat{\tau}, \tilde{\tau}^{p}(\eta)\right] \in B\left(\phi^{*}\right)$ if, and only if, $\eta \leq \eta^{*}$, which proves the claim.

Observing that the threshold $\eta^{*}$ does not depend on $\phi$ (since neither $\tilde{\tau}^{p}(\eta)$ nor $\bar{\tau}^{p}\left(\phi^{*}\right)$ depend on $\phi$ ), and combining Claims 3 and 4, we obtain that program (29) has a solution at $\phi=\phi^{*}$ if $\eta \leq \eta^{*}$, and that, vice versa, program (29) has no solution at $\phi=\phi^{*}$ if $\eta>\eta^{*}$.

Furthermore, by Claim 2, if program (29) has a solution at $\phi=\phi^{*}$, i.e. if $\eta \leq \eta^{*}$, then $\phi^{*} \geq \phi^{* *}$, where $\phi^{* *}$ is defined by (34). Conversely, if program (29) has no solution at $\phi=\phi^{*}$, i.e. if $\eta>\eta^{*}$, then $\phi^{*}<\phi^{* *}$. This proves the second part of Lemma 3.

\footnotetext{
${ }^{42}$ Note also that, because $\bar{\tau}^{p}\left(\phi^{*}\right)<\hat{\tau}$, we also have that $\tilde{\tau}^{p}\left(\eta^{*}\right)<\hat{\tau}$. This implies that $\tilde{\tau}^{p}\left(\eta^{*}\right)$ is a feasible tax rate, i.e. it does not violate the constraint that $\tau \leq \hat{\tau}$.
} 


\subsection{Proof of Proposition 2}

We begin by characterizing some preliminary results regarding the preferences of the elite over alternative pairs of strategies.

Claim 5 Strategy $\mathcal{N} \mathcal{A}$ is adopted by the elite if and only if $\phi \geq \min \left\{\phi^{*}, \phi^{* *}\right\}$.

Proof. When strategy $\mathcal{R}$ is feasible, the no-deviation condition from it of the elite is satisfied in any state including state $\mu=\mu^{w}$; moreover, the value that the elite get from a deviation in the state $\mu^{w},(19)$, is equal to the value that they get from $\mathcal{N} \mathcal{A},(14)$. This implies, when $\mathcal{R}$ is feasible, the value of $\mathcal{R}$ for the elite is always greater than the value of $\mathcal{N} \mathcal{A}$. By Lemma 1 , when $\mathcal{D}$ is feasible, the value of $\mathcal{D}$ for the elite is always greater than the value of $\mathcal{N} \mathcal{A}$. Also, combining Lemmas 1 and 3 , we have that either strategy $\mathcal{R}$ or strategy $\mathcal{D}$ is feasible if, and only if, $\phi \geq \min \left\{\phi^{*}, \phi^{* *}\right\}$.

Claim 5 implies that over the range $\phi \geq \min \left\{\phi^{*}, \phi^{* *}\right\}$, where either $\mathcal{R}$ or $\mathcal{D}$ are feasible, strategy $\mathcal{N} \mathcal{A}$ can be neglected. The next Claim characterizes the preferences of the elite when both $\mathcal{D}$ and $\mathcal{R}$ are feasible.

Claim 6 If both strategy $\mathcal{D}$ and the strategy $\mathcal{R}$ are feasible, i.e. if $\phi \geq \max \left\{\phi^{*}, \phi^{* *}\right\}$, then the elite always prefer strategy $\mathcal{R}$ over any other strategy.

Proof. Strategy $\mathcal{N} \mathcal{A}$ can of course be neglected. Both strategies $\mathcal{D}$ and $\mathcal{R}$ allow to win wars, but strategy $\mathcal{D}$ is less convenient for the elite since it involves always setting taxes at the maximum level $\hat{\tau}$ preferred by the citizens, rather than at incentive-compatible level preferred by the elite.

We can now use these preliminary results to prove Proposition 2.

The proof of Case 1a and Case 2a in Proposition 2 follows immediately from Claim 5. When $\phi<\min \left\{\phi^{*}, \phi^{* *}\right\}$, the elite choose no-action, and the best-response of the citizens is to put no effort in fighting. Hence, a transition to state $C$ occurs at time $t=T+1$.

The proof of Case 1b in Proposition 2 follows from Claim 5, which implies that strategy $\mathcal{N} \mathcal{A}$ is never chosen over the range $\phi \geq \phi^{* *}$. Also, when $\eta<\eta^{*}$, we have that $\phi^{* *}<\phi^{*}$ (by Lemma 3) which implies (by Claim 6) that strategy $\mathcal{D}$ is also never chosen by the elite for any $\phi \geq \phi^{* *}$. It follows that the elite choose in equilibrium strategy $\mathcal{R}$ for any $\phi \geq \phi^{* *}$. Moreover, because citizens are credibly promised an incentive-compatible redistribution, they always choose to put effort, which implies that $s_{t}=N$ for any $t \geq 0$. Finally, if a deviation from the equilibrium history in question, $\tilde{h}^{t-1}$, occurs, the citizens choose to put no effort in 
war again, and the elite always set $\tau=0$, which causes a transition to state $C$ in the period after a new war occurs. The proof of Case $2 \mathrm{c}$ is analogous.

The proof of Case $2 \mathrm{~b}$ in Proposition 2, follows from Claim 5, which implies the elite do no choose strategy $\mathcal{N} \mathcal{A}$ for any $\phi \geq \max \left\{\phi^{*}, \phi^{* *}\right\}$ and from Lemma 3, which implies that, when $\eta>\eta^{*}, \phi^{*}<\phi^{* *}$ and the elite choose strategy $\mathcal{D}$ rather then strategy $\mathcal{R}$ over the range $\left(\phi^{*}, \phi^{* *}\right)$ since the latter is not feasible. Moreover, because citizens are credibly promised democracy at period $T$, they always choose to put effort, which implies that $s_{T+1}=D$. If a deviation from the equilibrium history in question, $\hat{h}^{t-1}$, occurs, the citizens choose to put no effort in war again, the elite respond by setting always set $\tau=0$, which causes a transition to states $C$ in the period after a new war occurs.

Finally, the proof of Case 3 in Proposition 2 follows immediately from description of the equilibrium of the subgame beginning in state $\left(D, \mu^{u}\right)$ provided by Proposition 1 , which implies that $s_{t}=D$ for any $t>T+1$. 


\section{References}

Acemoglu, Daron and Robinson, James A. "Why Did the West Extend the Franchise? Democracy, Inequality, and Growth in Historical Perspective." Quarterly Journal of Economics, November 2000, 115(4), pp. 1167-99.

Acemoglu, Daron and Robinson, James A. "A Theory of Political Transitions." American Economic Review, September 2001, 91(4), pp. 938-63.

Acemoglu, Daron and Robinson, James A. Economic Origins of Dictatorship and Democracy. Cambridge: Cambridge University Press, 2006.

Andreski, Stanislav. Military Organization and Society. London: Routledge \& Kegan Paul, 2nd ed., 1968.

Besley, Timothy and Torsten Persson. "Wars and State Capacity." Mimeo, 2007.

Beukema, Herman. "Social and Political Aspects of Conscription: Europe's Experience." Military Affairs, Spring 1941, 5(1), pp. 21-31.

Boix, Carles. Democracy and Redistribution. Cambridge: Cambridge University Press, 2003.

Chari, V. V. and Patrick J. Kehoe. "Sustainable Plans." Journal of Political Economy, August 1990, 98(4), pp. 783-802.

Centeno, Miguel Angel. Blood and Debt. War and the Nation-State in Latin America. University Park, PA: The Pennsylvania State University Press, 2002.

Conley, John P. and Temimi, Akram. "Endogenous Enfranchisement When Groups Preferences Conflict." Journal of Political Economy, 2001, 109(1), pp. 79-102.

Dolman, Everett Carl. The Warrior State. New York, NY: Palgrave Macmillan, 2004.

Downing, Brian M. The Military Revolution and Political Change: Origins of Democracy and Autocracy in Early Modern Europe. Princeton, N.J.: Princeton University Press, 1992.

Fudenberg, Drew and Jean Tirole. Game Theory, Cambridge, MA: MIT Press, 1991.

Giddens, Anthony. The Nation-State and Violence. Volume Two of a Contemporary Critique of Historical Materialism. Berkeley and Los Angeles, CA: University of California Press, 1987.

Glaeser, Edward L. "The Political Economy of Warfare." NBER Working Paper No. 12738, December 2006.

Goldstein, Robert J. Political Repression in 19th Century Europe. London and Camberra: Croon Helm,1951.

Gradstein, Mark. "Inequality, Democracy and the Protection of Property Rights." Eco- 
nomic Journal, January 2007, 117(516), pp. 252-269.

Greif, Avner. Institutions and the Path to the Modern Economy. Lessons from Medieval Trade. Cambridge: Cambridge University Press, 2006.

Halperin, Sandra. War and Social Change in Modern Europe. The Great Transformation Revisited. Cambridge: Cambridge University Press, 2004.

Herbst, Jeffrey. States and Power in Africa. Comparative Lessons in Authority and Control. Princeton, NJ: Princeton University Press, 2000.

Hintze, Otto. Military Organisation and the Organisation of the State, in The Historical Essays of Otto Hintze. New York, NY: Oxford University Press, 1975.

Hobsbawm, Eric. Nations and Nationalism since 1780: Programme, Myth, Reality. Cambridge: Cambridge University Press, 1990.

Huntington, Samuel P. The Soldier and the State. The Theory and Politics of Civil-Military Relations. Cambridge, MA: The Belknap Press of Harvard University Press, 1957.

Jack, William and Lagunoff, Roger. "Dynamic Enfranchisement." Journal of Public Economics, May 2006, 90, pp. 551-572.

Jackson, Matthew and Morelli, Massimo. "Political Bias and War." American Economic Review, 2007, 97(4), pp. 1353-1373.

Kennedy, Paul. The Rise and Fall of Great Powers. Economic Change and Military Conflict from 1500 to 2000. New York, NY: Random House, 1987.

Keyssar, Alexander. The Right to Vote. The Contested History of Democracy in the United States. New York, NY: Basic Books, 2000.

Lizzeri, Alessandro and Persico, Nicola. "Why Did the elite Extend the Suffrage? Democracy and the Scope of Government with An Application to Britain's 'Age of Reform.'" Quarterly Journal of Economics, May 2004, 119(2), pp. 707-765.

Llavador, Humberto and Oxoby, Robert J. "Partisan Competition, Growth and the Franchise." Quarterly Journal of Economics, August 2005, 120(3).

Mann, Michael. States, War and Capitalism. Studies in Political Sociology. Oxford: Basic Blackwell Inc., 1988.

Marwick, Arthur. War and Social Change in the Twentieth Century: A Comparative History of Britain, France, Germany, Russia and the United States. London: Collier-Macmillan, 1974.

Meltzer, Allan H. and Richard, Scott F. "A Rational Theory of the Size of Government." Journal of Political Economy, October 1981, 89(5), pp. 914-27.

Porter, Bruce D. War and the Rise of the Modern State. The Military Foundations of 
Modern Politics. New York, N.Y.: The Free Press, 1994.

Reiter, Dan and Stam, Allan C. Democracies at War. Princeton, N.J.: Princeton University Press, 2002.

Roberts, Kevin. "Voting over Income Tax Schedules." Journal of Public Economics, 1977, 8, pp. 329-340.

Romer, Thomas. "Individual Welfare, Majority Voting, and the Properties of a Linear Income Tax," Journal of Public Economics, 1975, 7, pp. 163-185.

Skocpol, Theda. States and Social Revolutions. Cambridge: Cambridge University Press, 1979

Therborn, Goran. "The Rule of Capital of the Rise of Democracy." New Left Review, 1977, 103, pp. 3-41.

Ticchi, Davide and Andrea Vindigni. "On Wars and Political Development. The Role of International Conflicts in the Democratization of the West." Faculty of Economics, University of Urbino, Working Paper 81, August 2003.

Tilly, Charles (Editor). The Formation of National States in Western Europe. Princeton, N.J.: Princeton University Press, 1975.

Tilly, Charles. Coercion, Capital and European State, AD 990-1992. Cambridge, MA: Blackwell, 1990.

Titmuss, Richard M. Essays on the Welfare State. London: George Allen \& Unwin Ltd, 1958.

Weber, Max. General Economic History. Glencoe, IL: The Free Press, 1950. 